уДК 556.314(571/5)

\title{
ПЕРВЫЕ ДАННЫЕ ПО ИЗОТОПНОМУ СОСТАВУ ПЛАСТОВЫХ ВОД РАЗРАБАТЫВАЕМЫХ НЕФТЯНЫХ МЕСТОРОЖДЕНИЙ НОВОСИБИРСКОЙ ОБЛАСТИ
}

\author{
Новиков Дмитрий Анатольевич1,2, \\ NovikovDA@ipgg.sbras.ru
}

\author{
Пыряев Александр Николаевич3,2, \\ pyrayev@igm.nsc.ru
}

Черных Анатолий Витальевич ${ }^{1}$,
ChernykhAV@ipgg.sbras.ru

Дульцев Федор Федорович 1 , DultsevFF@ipgg.sbras.ru

Рыжкова Светлана Владимировна ${ }^{1,2}$, RizhkovaSV@ipgg.sbras.ru

1 Институт нефтегазовой геологии и геофизики им. А.А. Трофимука СО РАН, Россия, 630090, г. Новосибирск, пр. Академика Коптюга, 3.

2 Новосибирский национальный исследовательский государственный университет, Россия, 630090, г. Новосибирск, ул. Пирогова, 1.

3 Институт геологии и минералогии им. В.С. Соболева СО РАН, Россия, 630090, г. Новосибирск, пр. Академика Коптюга, 3.

\begin{abstract}
Актуальность исследования состоит в решении вопросов изотопной геохимии подземных вод нефтегазоносных отложений крупных артезианских бассейнов. Воды нефтегазоносных отложений рассматриваемого региона практически не изучены с точки зрения распределения стабильных изотопов $\left(\delta D, \delta^{18} \mathrm{O}, \delta^{13} \mathrm{C}\right)$ и изотопных отношений ${ }^{87} \mathrm{Rb} /{ }^{36} \mathrm{Sr} u^{87} \mathrm{Sr} /{ }^{186} \mathrm{Sr}$.

Цель: выявление особенностей генезиса подземных вод и взаимодействия в системе «вода - горная порода» с позиций изотопной геохимии.

Методы. Анализ комплекса $\delta D, \delta^{18} \mathrm{O}, \delta^{13} \mathrm{C}$ II вод и растворенного неорганического углерода (Dissolved Inorganic Carbon (DIC)) проводился в иентре коллективного пользования Института геологии и минералогии им. В.С. Соболева СО РАН с помощью nрибора Isotope Ratio Mass Spectrometer Finnigan ${ }^{T M}$ MAT 253. Изотопные отношения ${ }^{87} \mathrm{Sr}{ }^{86} / \mathrm{Sr}$ и ${ }^{87} \mathrm{Rb} /{ }^{86} \mathrm{Sr}$ изучались на массспектрометре MI 1201 в в двхленточном режиме с регистрацией на одном коллекторе.

Результаты. Изучены $\delta D, \delta^{18} \mathrm{O}, \delta^{13} \mathrm{C}_{\mathrm{DIC}},{ }^{87} \mathrm{Sr}{ }^{86} \mathrm{Sr}$ и отношения изотопов $u^{87} \mathrm{Rb} /{ }^{86} \mathrm{Sr}$ для вод разрабатываемых нефттяных месторождений Новосибирской области. Показано наличие в гидрогеологическом разрезе двух основных генетических типов подземных вод: древних инфильтрогенных и седиментогенных. Для большинства изученных вод пара $\delta D-\delta^{18} \mathrm{O}$ указывает на сочетание двух определяющих фракторов: исходное обеднение вод легким изотопом ${ }^{16} \mathrm{O}$ в период «до захоронения» на величину до 4-5\% в результате климатического воздействия; дальнейшее насьщение вод тяжельм изотопом ${ }^{18} \mathrm{O}$ в ходе длительного WRI, приведшее к утяжелению изотопного состава при умеренных условиях на дополнительные 2-3\%. Значения $\delta^{13} C_{D I C}$ ряда вод позволили предположить бактериальное происхождение водорастворенной уелекислоты. Для вод, температура

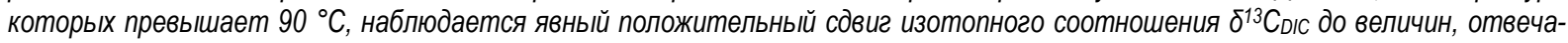
ющих «нормальным» значениям углеродных дельт в термальных водах: от -8 до +4 \%о VPDB. Для исследованных подземных вод характерно низкое значение отношения ${ }^{87} \mathrm{Sr} /{ }^{86} \mathrm{Sr}$ относительно вод современного океана. Предполагается значительный вклад мантийных источников стронция, проявляющегося в разной степени для вод различных месторождений.
\end{abstract}

\section{Ключевые слова:}

Подземные воды, $\delta^{18} \mathrm{O}, \delta \mathrm{D}, \delta^{13} \mathrm{C}$, изотопные отношения ${ }^{87} \mathrm{Sr} 86 / \mathrm{Sr} u^{87} \mathrm{Rb} /{ }^{86} \mathrm{Sr}$, взаимодействие в системе «вода - горная порода», разрабатьваемые залежи, нефтяное месторождение, Новосибирская область, Западная Сибирь.

\section{Введение}

В работе представлены первые данные по концентрациям $\delta^{18} \mathrm{O}, \delta \mathrm{D}, \delta^{13} \mathrm{C}$ и изотопным отношениям ${ }^{87} \mathrm{Rb}^{86} / \mathrm{Sr}$ и ${ }^{87} \mathrm{Sr}^{86} / \mathrm{Sr}$ в водах разрабатываемых залежей нефтяных месторождений Новосибирской области. Вопросы генезиса подземных вод нефтегазоносных бассейнов в науке в настоящее время активно обсуждаются. Комплексный анализ $\delta^{18} \mathrm{O}, \delta \mathrm{D}, \delta^{13} \mathrm{C}$ широко применяется в исследованиях генезиса, динамики подземных вод и процессов их взаимодействия с вмещающими горными породами [1].
В настоящее время на территории Новосибирской области в разработке находятся три нефтяных месторождения: Верх-Тарское, Восточно-Тарское и Малоичское (рис. 1). На Верх-Тарском и Восточно-Тарском месторождениях эксплуатируются залежи горизонта $\mathrm{Ю}_{1}$ верхнеюрского возраста, а на Малоичском - внутрипалеозойская залежь. Также на Верх-Тарском промысле в разработке находится залежь горизонта НГГЗК (по Е.Е. Даненбергу и А.Э. Конторовичу зона контакта отложений палеозоя и мезозоя или разновозрастный нефтегазоносный горизонт зоны контакта $[2,3])$. 
Горизонт $Ю_{1}$ оксфордского регионального резервуара является основным продуктивным пластом и объектом разработки в исследуемом районе. Залежи разрабатываемых месторождений к настоящему времени практически полностью разбурены сеткой эксплуатационных скважин. Так, общий фонд скважин залежи пластов $\mathrm{Ю}_{1}{ }^{1}$ и $\mathrm{Ю}_{1}{ }^{2}$ Верх-Тарского нефтяного месторождения по состоянию на январь 2019 г. составляет 175 единиц, из них 134 действующих [4]. По состоянию на 01.01.2018 г. ее запасы нефти составляют: по категориям $\mathrm{A}+\mathrm{B}_{1}$ (геологические/извлекаемые) $39,980 / 10,898$ млн т, по категории $\mathrm{B}_{2}-1,180 / 0,489$ млн т [5]. Последние результаты детальных геотермических, гидродинамических и гидрогеохимических исследований нефтегазоносных отложений изучаемого региона отражены в работах [6-10].

\section{Фактический материал и методика исследований}

В 2019 г. в ходе экспедиционных работ на Малоичском, Восточно-Тарском и Верх-Тарском нефтяных месторождениях было отобрано 18 проб из разных водоносных горизонтов. Дополнительно в сравнительный анализ было привлечено 9 проб подземных вод из неокомских (Северо-Кеумское, Среднекеумское, Юганское месторождения) и нижне-среднеюрских (ЗападноГерасимовское месторождение) резервуаров. Лабораторное изучение химического состава методами титриметрии, ионной хроматографии, масс-спектрометрии с индуктивно связанной плазмой (ИСП) проводилось в Проблемной научно-исследовательской лаборатории гидрогеохимии Инженерной школы природных ресурсов ТПУ (аналитики О.В. Чеботарева, Н.В. Бублий, А.С. Погуца, В.В. Куровская, К.Б. Кривцова, Л.А. Ракул).

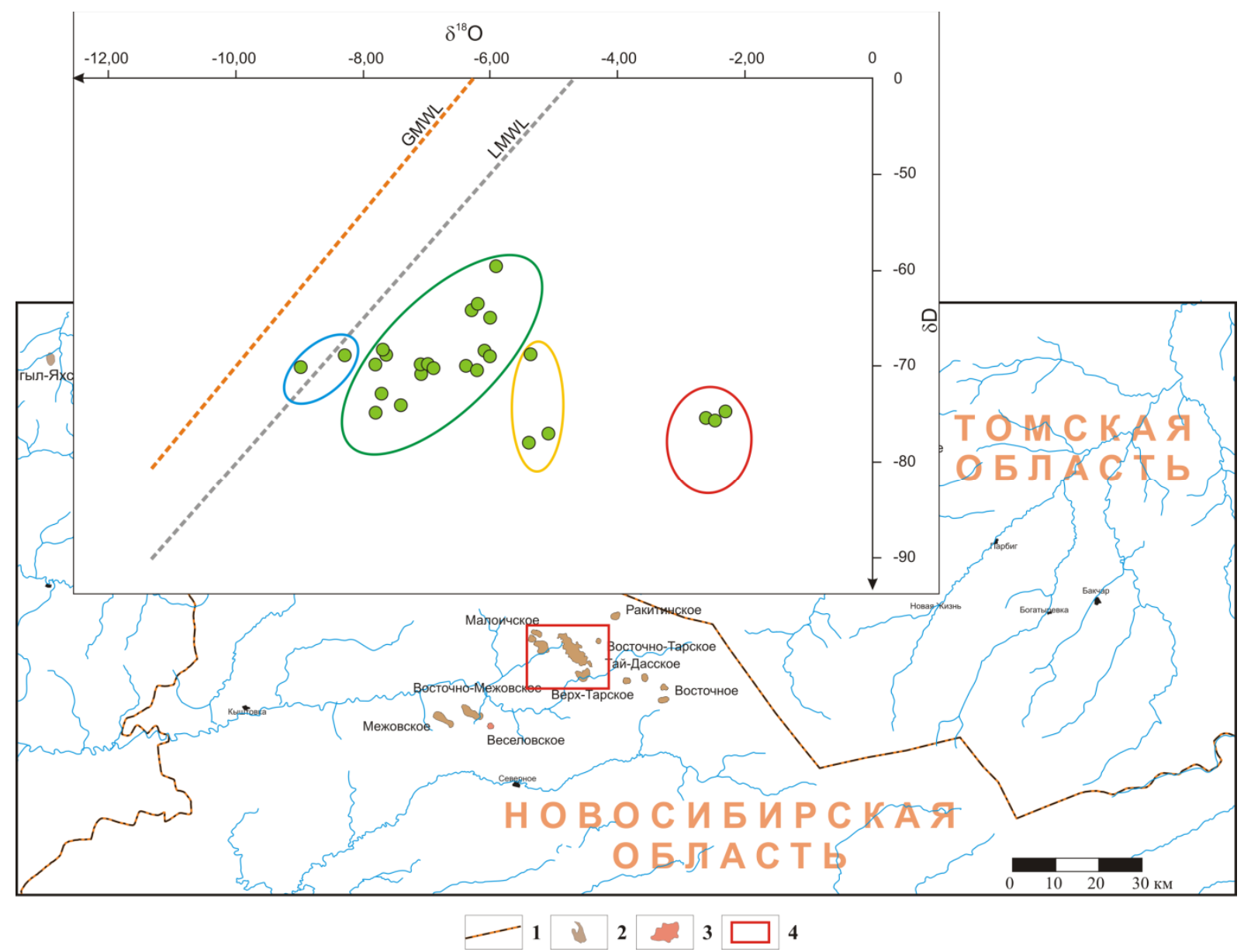

Pис. 1. Зависимость $\delta D=f\left(\delta^{18} O\right)$ для подземных вод разрабатываемых нефтяных месторождений Новосибирской области относительно GMWL и LMWL. 1 - административные границы; месторождения: 2 - нефтяные, 3 - газоконденсатные и газовые; 4 - район исследований. Пояснения к дополнительным обозначениям (эллипсам) - в тексте. Линии: оранжевая - GMWL, серая - LMWL

Fig. 1. Dependence $\delta D=\mathrm{f}\left(\delta^{18} O\right)$ for groundwater of the developed oil fields of the Novosibirsk region relative to GMWL and LMWL. 1 -administrative boundaries; fields: 2 - oil, 3 - gas condensate and gas; 4 - research area. Explanations for additional symbols (ellipses) see in the text. Lines: orange-GMWL, gray - LMWL

Анализ комплекса $\delta \mathrm{D}, \delta^{18} \mathrm{O}, \delta^{13} \mathrm{C}_{\mathrm{DIC}}$ вод и растворенного неорганического углерода (Dissolved Inorganic Carbon (DIC)) проводился в центре коллективного пользования Института геологии и минералогии им.
B.С. Соболева СО РАН с помощью прибора Isotope Ratio Mass Spectrometer Finnigan ${ }^{\mathrm{TM}}$ MAT 253, снабженного приставками пробоподготовки H/Device (для анализа $\delta \mathrm{D})$ и GasBench II (для анализа $\delta^{18} \mathrm{O}$ и $\delta^{13} \mathrm{C}_{\mathrm{DIC}}$ ). 
Значения $\delta^{13} \mathrm{C}_{\mathrm{DIC}}, \delta \mathrm{D}$ и $\delta^{18} \mathrm{O}$ измерялись относительно мировых стандартов: VSMOW2; SLAP2; GISP - для анализа водорода и кислорода; NBS-18; NBS-19 - для анализа $\delta^{13} \mathrm{C}_{\mathrm{DIC}}$. Ошибка определения изотопного состава стандартов по углероду и кислороду - не более $0,1 \%$, по водороду - не более 0,5 \%. Изотопные отношения ${ }^{87} \mathrm{Sr}^{86} / \mathrm{Sr}$ и ${ }^{87} \mathrm{Rb} /{ }^{86} \mathrm{Sr}$ изучались на массспектрометре MI 1201T в двухленточном режиме с регистрацией на одном коллекторе. Погрешность определения отношения ${ }^{87} \mathrm{Rb} /{ }^{86} \mathrm{Sr}$ не превышает $1 \%$.

\section{Результаты исследований и обсуждение}

Стабильные изотопы кислорода, водорода и углерода подземных вод и растворенной углекислоты

Как оказалось, значения $\delta^{18} \mathrm{O}, \delta \mathrm{D}$ и $\delta^{13} \mathrm{C}$ вод и водорастворенной углекислоты для нефтегазоносных отложений рассматриваемого региона мало изучены. Величины $\delta^{18} \mathrm{O}, \delta \mathrm{D}$ и $\delta^{13} \mathrm{C}$ позволяют определить генезис вод [11], исследовать процессы водосбора [12], взаимодействия вод с окружающими газами $[13,14]$ и породами (WRI - Water-rock interaction) [15-17].

Согласно литературным данным [12-16, 18 и др.] источником подземных вод в большинстве случаев выступают метеорные воды. Авторы работ $[12,16,19]$ активно оперируют парой $\delta^{18} \mathrm{O}$ и $\delta \mathrm{D}$ для построения локальных линий метеорных вод - LMWL, отражающих среднегодовое соотношение между изотопами водорода и кислорода в метеорных водах конкретного региона. Как правило, при подобных построениях делается сравнение тренда LMWL с глобальной линией метеорных вод (GMWL), предложенной Г. Крейгом в 1961 г. [18] и описываемой уравнением: $\delta \mathrm{D}=8 \cdot \delta^{18} \mathrm{O}+10$. Исходя из положения точек относительно линии Крейга, можно сделать выводы о климатических особенностях изучаемого региона в условиях осадконакопления [12], об интенсивности испарения вод и их газообмена с окружением [13], и о взаимодействии вод с породами.

Результаты анализа стабильных изотопов $\mathrm{O}$ и $\mathrm{H}$ изученных вод нефтяных месторождений Новосибирской области представлены в таблице. Из таблицы видно, что для вод изученного региона характерна довольно узкая вариация значений $\delta \mathrm{D}$ (от $-77,9 \%$ до $-61,7 \%$ и и $\delta^{18} \mathrm{O}($ от $-9,0 \%$ до $-5,1 \%$ \%). Анализ диаграммы $\delta \mathrm{D}=\mathrm{f}\left(\delta^{18} \mathrm{O}\right)$ (рис. 1) показал, что для большинства исследованных вод пара $\delta \mathrm{D}-\delta^{18} \mathrm{O}$ располагается значительно ниже как глобальной линии метеорных вод, так и LMWL: $\delta \mathrm{D}=7,5 \cdot \delta^{18} \mathrm{O}+5$ [20].

В литературе положительные отклонения от линии Крейга зачастую интерпретируют эффектом испарения вод, при котором происходит обеднение вод легким изотопом ${ }^{16} \mathrm{O}[19,21-23]$. В работе [13] было показано, что при небольшой глубине водоема (до 1 м) в современных условиях эффект испарения может приводить к дефициту легкого изотопа кислорода до 4 \%. Кроме эффекта испарения, положительные отклонения $\delta^{18} \mathrm{O}$ ряд исследователей объясняют изотопным обменом вод с окружающими породами [15-17]. Ве- личина эффекта изотопного обмена кислородом вод при WRI определяется множеством факторов (температура, давление, время взаимодействия, тип пород, соотношение вода/порода) и может достигать в естественных условиях 8 \% [24]. Тем не менее столь существенные изотопные сдвиги наблюдаются лишь в системах с экстремальными условиями. Например, в работе [15] показано, что при равновесном обмене вод с породами при температурах выше $221^{\circ} \mathrm{C}$ величина изотопного сдвига $\delta^{18} \mathrm{O}$ достигает примерно $+5,5$ \%. В нашем случае положительное отклонение кислородной дельты составляет от $+1,5$ \% для вод верхнеюрского и апт-альб-сеноманского комплексов Верх-Тарского месторождения (синий эллипс) и до $+5,8$ для вод нижне-среднеюрского комплекса Западно-Герасимовского месторождения (зеленый и оранжевый эллипсы). Отдельно стоит отметить воды палеозойского комплекса Малоичского месторождения, для которых профицит тяжелого изотопа ${ }^{18} \mathrm{O}$ составляет феноменальные $+(8,28-8,55)$ \% (красный эллипс).

Интересно отметить, что нарастание отклонения значений $\delta^{18} \mathrm{O}$ от линий метеорных вод коррелирует с возрастом водоносных комплексов (рис. 2, a). Причинами таких явлений могут быть как климатические изменения текущих условий относительно условий захоронения вод, так и процессы WRI.

Рассмотрим эти два фактора подробней. Из данных, представленных на рис. 1, видно, что для двух проб положительный сдвиг значений $\delta^{18} \mathrm{O}$ очень незначителен и вполне достоверно описывается линией локальных метеорных вод (синий эллипс). Повидимому, для этих двух проб, несмотря на довольно большую глубину залегания комплексов (734-1532 м для вод апт-альб-сеноманского и 2522-2532 м для вод верхнеюрского комплексов Верх-Тарского месторождения) характерно смешивание с метеорными водами. Как известно, апт-альб-сеноманские отложения изучаемого региона формировались преимущественно в континентальных фациях и их воды имеют древний инфильтрационный генезис [25].

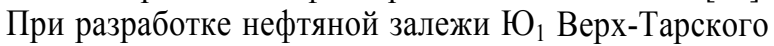
месторождения на начальных этапах в качестве агента заводнения выступали воды апт-альбсеномана. Поэтому получаемые значения пары $\delta^{18} \mathrm{O}$ и $\delta \mathrm{D}$ изученных проб отражают процессы этого смешения. Аналогичный эффект смешивания вод древних комплексов с более молодыми, вероятно, проявляется и для образца, отобранного в зоне контакта палеозойского фундамента и мезозойского осадочного чехла (НГГЗК) Верх-Тарского месторождения: несмотря на больший возраст вмещающих пород, значение $\delta^{18} \mathrm{O}$ остается на уровне вод верхнеюрского комплекса (рис. 2, а, красный эллипс), в то время как при переходе к водам более древних комплексов наблюдается явное насыщение кислорода вод изотопом ${ }^{18} \mathrm{O}$. 


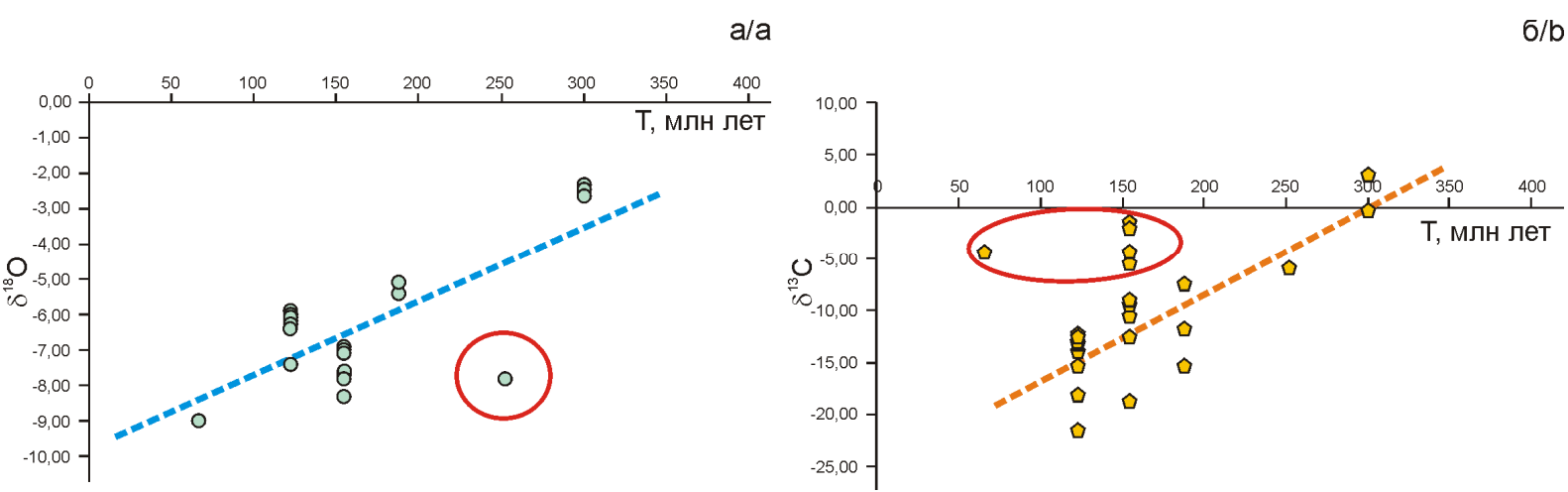

Pис. 2. Изменение значений $\delta^{18} O$ (a) $u^{13} C_{\text {DIC }}$ (б) изученных вод в зависимости от возраста вмещающих отложений. Линии - обобщающие тренды. Красными эллипсами выделены точки, значительно отклоняюшиеся от общей корреляции

Fig. 2. Changes in the ratios of $\delta^{18} O(a)$ and ${ }^{13} C_{D I C}$ (b) values of the studied samples depending on the age of the host sediments. Lines reftect the generalizing trends. The points that deviate significantly from the general correlation are marked with red ellipses

Таблица. Изотопные характеристики подземных вод разрабатываемых месторождений Новосибирской области Table. Isotopic characteristics of groundwaters of the developed deposits of the Novosibirsk region

\begin{tabular}{|c|c|c|c|c|c|c|c|c|c|c|}
\hline $\begin{array}{l}\text { № пробы } \\
\text { Sample no. }\end{array}$ & $\begin{array}{l}\text { Месторождение } \\
\text { Field }\end{array}$ & $\begin{array}{c}\text { Комплекс } \\
\text { Complex }\end{array}$ & $\mathrm{T},{ }^{\circ} \mathrm{C}$ & $\begin{array}{l}\mathrm{M}, \text { г/дм } \\
\text { TDS, g/1 }\end{array}$ & $\delta^{13} \mathrm{C}_{\mathrm{DIC}}$ (VPDB),$\%$ & $\begin{array}{c}\delta \mathrm{D}_{\text {(VSMOW) }}, \\
\% \text { o }\end{array}$ & $\begin{array}{c}\delta^{18} \mathrm{O}_{\text {(VSMOW) }} \\
\% \text { \% }\end{array}$ & ${ }^{87} \mathrm{Rb} /{ }^{86} \mathrm{Sr}$ & ${ }^{87} \mathrm{Sr} /{ }^{86} \mathrm{Sr}$ & $\pm 2 \mathrm{SD}$ \\
\hline 6 & $\mathrm{I}$ & $\mathrm{A}$ & 40 & 22 & $-4,4$ & $-74,3$ & $-9,0$ & 0,00291 & 0,70652 & 0,00002 \\
\hline 2439 & IV & \multirow{9}{*}{ B } & 82 & 18 & $-18,1$ & $-61,7$ & $-5,9$ & - & - & - \\
\hline 2440 & IV & & 82 & 21 & $-13,2$ & $-64,9$ & $-6,0$ & - & - & - \\
\hline 2441 & IV & & 82 & 16 & $-12,6$ & $-68,9$ & $-6,0$ & 0,01114 & 0,70708 & 0,00001 \\
\hline 2470 & $\mathrm{~V}$ & & 94 & 15 & $-13,4$ & $-64,3$ & $-6,2$ & - & - & - \\
\hline 2471 & $\mathrm{~V}$ & & 94 & 13 & $-14,0$ & $-65,4$ & $-6,3$ & - & - & - \\
\hline 2525 & IV & & 82 & 13 & $-15,4$ & $-70,3$ & $-6,2$ & - & $\begin{array}{llll}- & & & \end{array}$ & - \\
\hline 2526 & IV & & 82 & 16 & $-21,6$ & -74 & $-7,4$ & - & - & - \\
\hline 2527 & IV & & 82 & 21 & $-13,2$ & $-68,3$ & $-6,1$ & - & $\begin{array}{ll}- \\
\end{array}$ & - \\
\hline 2528 & VI & & 81 & 16 & $-12,4$ & $-69,8$ & $-6,4$ & 0,00976 & 0,70530 & 0,00007 \\
\hline 115 & $\mathrm{I}$ & \multirow{10}{*}{$\mathrm{C}$} & 91 & 34 & $-9,1$ & $-72,8$ & $-7,7$ & - & - & - \\
\hline 145 & I & & 88 & 28 & $-10,5$ & $-70,4$ & $-8,3$ & - & - & - \\
\hline 152 & I & & 88 & 36 & $-18,8$ & $-71,8$ & $-6,9$ & - & - & - \\
\hline 162 & I & & 92 & 34 & $-5,5$ & $-70,7$ & $-7,1$ & 0,00230 & 0,70654 & 0,00003 \\
\hline 172 & I & & 94 & 35 & $-9,5$ & $-74,7$ & $-7,8$ & 0,00197 & 0,70657 & 0,00004 \\
\hline 375 & I & & 89 & 38 & $-9,1$ & $-69,5$ & $-7,7$ & 0,00235 & 0,70610 & 0,00005 \\
\hline 379 & I & & 93 & 38 & $-4,4$ & $-71,5$ & $-7,0$ & 0,00231 & 0,70664 & 0,00006 \\
\hline 1015 & I & & 90 & 46 & $-1,4$ & $-70,8$ & $-7,1$ & 0,00223 & 0,70659 & 0,00003 \\
\hline 19 & II & & 81 & 38 & $-12,6$ & $-71,1$ & $-7,6$ & - & - & - \\
\hline 102 & II & & 81 & 36 & $-2,0$ & $-70,1$ & $-7,7$ & 0,00223 & 0,70644 & 0,00003 \\
\hline 2522 & VII & \multirow{3}{*}{ D } & 96 & 22 & $-15,4$ & $-68,7$ & $-5,4$ & - & - & - \\
\hline 2523 & VII & & 96 & 22 & $-7,4$ & -77 & $-5,1$ & 0,01111 & 0,70638 & 0,00007 \\
\hline 2524 & VII & & 96 & 21 & $-11,8$ & $-77,9$ & $-5,4$ & - & - & - \\
\hline 700 & I & $\mathrm{E}$ & 109 & 37 & $-6,0$ & $-71,5$ & $-7,8$ & 0,00277 & 0,70614 & 0,00004 \\
\hline 25 & III & \multirow{3}{*}{$\mathrm{F}$} & 94 & 72 & $-0,4$ & $-76,8$ & $-2,3$ & - & - & - \\
\hline 11 & III & & 94 & 70 & 3,1 & $-77,3$ & $-2,5$ & 0,00988 & 0,70778 & 0,00004 \\
\hline 27 & III & & 94 & 71 & $-0,3$ & $-77,0$ & $-2,6$ & - & - & - \\
\hline
\end{tabular}

Примечание: месторождения: I- Верх-Тарское, II - Восточно-Тарское, III- Малоичское, IV - Северо-Кеумское, VСреднекеумское, VI- Юганское (11 лищензионный участок), VII-Западно-Герасимовское; водоносный комплекс: Aапт-альб-сеноманский, $B$ - неокомский, $C$-верхнеюрский, $D$ - нижне-среднеюрский, $E$ - зона контакта с палеозоем (НГГЗК), F-девонский; «-»-не определялось.

Note: fields: I - Verkh-Tarskoe, II - Vostochno-Tarskoe, III - Maloichskoe, IV - Severo-Keumskoe, V-Srednekeumskoe, VI-Yuganskoe (11 licensed area), VII - Zapodno-Gerasimovskoe; aquifer: A - Aptian-Albian-Cenomanian, B - Neocomian, C-Upper Jurassic, D - Lower-Middle Jurassic, E - contact zone with the Paleozoic (NGGZK), F-Devonian; «-» - not determined.

Так, для вод неокомского и верхнеюрских комплексов исследованных месторождений можно наблюдать уже существенное положительное отклонение изотопного состава кислорода, варьирующее от $+2,3$ до 3,8 \% (рис. 1, зеленый эллипс). Согласно работе [26] в тоарском веке $(182,7-174,1$ млн лет) кли- мат претерпевал существенные изменения: температура и влажность воздуха увеличились скачкообразно относительно позднетриасовой - раннеюрской фазы холодов [27]. Очевидно, что рост среднегодовой температуры при смене геологических эпох должен был способствовать прогрессированию эффекта испаре- 
ния вод с поверхностей древних водоемов, из которого следует повышенная влажность воздуха древнего климата и, что важнее в нашем случае, сильное обеднение вод этих водоемов легкими изотопами кислорода. Логично предположить, что при захоронении сингенетичных вод значения $\delta^{18} \mathrm{O}$ в них должны быть смещены относительно современной GMWL в положительную сторону. При этом чем больше была температура гипотетического древнего климата, тем сильней должен быть изотопный кислородный сдвиг относительно линии Крейга. На рис. 1 можно видеть, что для проб, отобранных из нижне-среднеюрского комплекса (оранжевый эллипс), отвечающих как раз гипотетическому скачкообразному потеплению климата в тоарском веке, наблюдается дальнейшее увеличение положительного сдвига $\delta^{18} \mathrm{O}$. Еще больший дефицит изотопа ${ }^{16} \mathrm{O}$ наблюдается для вод девонских отложений Малоичского месторождения (красный эллипс). Девон является довольно спорной с точки зрения климата и температур эпохой, учитывая активную вулканическую деятельность. Отсюда многие работы указывают на то, что в это время температура атмосферы была в среднем выше текущей среднегодовой. Так, симуляции изменения температуры в течение девонского периода, основанные на вариации содержания $\mathrm{CO}_{2}$ в древней атмосфере, показали, что средняя температура поверхности Земли оставалась очень близка к постоянной: $23,4,23,5$ и 22,2 для LP1, LP2 и LP3, соответственно [28]. А в работе [29] было показано, что средняя температура поверхности океана в верхнедевонское время колебалась в диапазоне 27-34 ${ }^{\circ} \mathrm{C}$. Наиболее наглядно выглядит зависимость температурных аномалий девонского периода, представленная авторами работы [30], согласно которой положительные отклонения температуры атмосферы относительно современной в период 350-420 млн лет составляли от 0 до $6{ }^{\circ} \mathrm{C}$. Как отмечено выше, в нашем случае захороненные воды относятся к комплексам с положительными климатическими температурными сдвигами относительно современных условий. Вероятно, относительно более высокая температура климата во времена захоронения сингенетичных вод сыграла определенную роль в изменении изотопного состава кислорода и привела к его положительному сдвигу относительно GMWL.

Тем не менее столь значительные отклонения значений $\delta^{18} \mathrm{O}$, наблюдаемые для изученных объектов (особенно в случае вод девонского комплекса), повидимому, не могут быть результатом исключительно климатических изменений. Принимая во внимание довольно высокие температуры исследованных вод и длительный период взаимодействия вод с вмещающими породами, можно сделать предположение об изменении изотопного состава кислорода вод, в том числе и за счет взаимодействия в системе «водапорода» - WRI. При этом с увеличением возраста водовмещающих пород пропорционально растет и содержание тяжелого изотопа ${ }^{18} \mathrm{O}$ в водах (рис. $2, a$ ). Как уже было описано ранее, для систем с экстремальными условиями (высокие температуры и давления) положительные изотопные сдвиги кислорода вод могут достигать в естественных условиях 8 \%о [24]. Тем не менее для достижения подобных изотопных эффектов температура вод должна превышать $200{ }^{\circ} \mathrm{C}$. В нашем случае, при современных температурах вод от 40 до $109{ }^{\circ} \mathrm{C}$ (таблица), величина изотопного сдвига кислорода в водах девонского комплекса составляет более 8 \%. Наиболее достоверным объяснением подобных аномальных проявлений изотопного состава представляется сочетание двух влияющих факторов: 1) исходное обеднение вод легким изотопом ${ }^{16} \mathrm{O}$ в период «до захоронения» на величину до 4-5 \%о в результате климатического воздействия; 2) дальнейшее насыщение вод тяжелым изотопом ${ }^{18} \mathrm{O}$ в ходе длительного WRI, приведшее к утяжелению изотопного состава при умеренных условиях на дополнительные 2-3 \% .

Интерпретацию взаимодействия вод с окружением, в том числе и WRI, зачастую проводят на основании значений $\mathrm{d}^{13} \mathrm{C}_{\mathrm{DIC}}$, поскольку круг источников гидрокарбонат-иона в природных водах ограничен, хотя и довольно разнообразен: атмосферный $\mathrm{CO}_{2}$ [14, 31-33], биогенная углекислота, выделяемая растениями (вегетационная) [34] и микроорганизмами (бактериальная) [35] в результате их жизнедеятельности и переработки органического вещества [36], выветривание карбонатных и силикатных пород [31], почвенный $\mathrm{CO}_{2}$ [37], гидрокарбонат-ион, образуемый при гидролизе алюмосиликатов [31] и растворении карбонатов $[36,37]$. В ряде случаев приходится также учитывать техногенные источники [14]. Разумеется, что полный спектр перечисленных источников углекислоты в природных водах встречается редко. В большинстве случаев доминирует лишь часть из них, при этом вклад остальных остается на следовом уровне и, как правило, не учитывается. Так, в нашем случае становится очевидным, что основными источниками углекислоты пластовых вод разрабатываемых нефтяных месторождений Новосибирской области могут служить лишь несколько: биогенная (бактериальная) углекислота, $\mathrm{CO}_{2}$, высвобождаемый при углефикации и термическом распаде органического вещества, а также диоксид углерода, формируемый при гидролизе алюмосиликатов и растворении карбонатов. Такие источники, как атмосферный углекислый газ, вегетативная углекислота и почвенный $\mathrm{CO}_{2}$, пенетрирующие, очевидно, лишь на небольшие глубины, в формировании DIC изученных подземных вод принимают минимальное участие.

Принимая во внимание «нефтяное происхождение» исследуемых вод, можно сделать вывод о превалировании бактериальной активности в процессах формирования DIC: обилие органического вещества, анаэробные условия и закрытый резервуар должны способствовать развитию бактериальных колоний и прогрессированию их жизнедеятельности. Тем не менее стоит упомянуть неблагоприятные для типичной бактериальной активности температурные условия рассматриваемых водоносных комплексов. Процессы, связанные с биологическим преобразованием органического вещества (OB), очень сложны и включают в себя многостадийные процессы: гидролиз, кислотоге- 
нез, ацетогенез и метаногенез [38, 39]. При этом нормальными условиями для функционирования бактериальных систем считаются $55-60{ }^{\circ} \mathrm{C}$, в то время как для исследуемых систем диапазон температур существенно выше (в среднем от 81 до $109{ }^{\circ} \mathrm{C}$ ) и, повидимому, непригоден для жизнедеятельности типичных бактерий-гетеротрофов. Исключение составляют лишь воды апт-альб-сеноманского комплекса Верх-Тарского месторождения, температура которых составляет $40{ }^{\circ} \mathrm{C}$. Но, как уже упоминалось ранее, низкая температура вод этого комплекса может быть следствием смешения сингенетичных вод комплекса с метеорными. Исходя из вышеописанного, биогенное (бактериальное) происхождение растворенной в водах углекислоты, на первый взгляд, представляется маловероятным.

Изотопные концентрации углерода-13 в DIC исследованных вод находятся в довольно широком интервале значений и колеблются от $-21,6$ до $+3,1 \%$ (таблица). При этом наблюдается закономерное обогащение значений $\delta^{13} \mathrm{C}_{\text {DIC }}$ тяжелым изотопом ${ }^{13} \mathrm{C}$ при переходе от вод молодых комплексов к более древним (рис. 2, б). На первый взгляд, вопрос происхождения DIC и значений его изотопных дельт остается не вполне понятным. Преобразование ОВ в углекислоту без непосредственного участия биоты затруднительно Изотопная характеристика термальных источников различных регионов мира показывает, что в большинстве случаев значения $\delta^{13} \mathrm{C}_{\mathrm{DIC}}$ колеблются в намного более узких интервалах значений: от $-8,4$ до $+1,7 \%$ для источников Ладакха, Хамачал [40], Гарвальских Гималаев [41] в Индии, от $-2,3$ до $+4,7 \%$ для Йеллоустонских источников и связанных с ними травертинов [42] в США, -8,4 \%о в водах Фитеро [43] в Испании, от $+6,26$ до $+8,07 \%$ в термальных водах Памуккале (Турция) [44], от $-0,1$ до $+3,5$ \%о для источника Эрегсалок в Венгрии [45]. Получаемый диапазон значений $\delta^{13} \mathrm{C}_{\text {DIC }}$ авторы трактуют как результат смешения метеорных вод с углекислотой метаморфических флюидов. Считается, что высвобождающийся при дегазации мантии $\mathrm{CO}_{2}$ имеет значения $\delta^{13} \mathrm{C} \sim-8 \%$ VPDB $[41,46]$. В работе [47] дается диапазон от -1,6 до -10,8 \%. Протекающие коровые процессы и связанные с ними процессы метаморфической декарбонации приводят к обогащению отношения тяжелым изотопом ${ }^{13} \mathrm{C}$ и смещению изотопного отношения до положительных значений. В целом для диапазона $\delta^{13} \mathrm{C}_{\text {DIC }}$ термальных вод от -8 до $+4 \%$ VPDB вклад биологической активности принимается несущественным [40, 41, 48].

В работе [49] исследованы термальные воды Непала со значениями $\delta^{13} \mathrm{C}_{\mathrm{DIC}}$, варьирующими в более широком диапазоне: от $-13,0$ до $+13,5$ \%. Авторы работы предполагают, что подобное обогащение изотопного отношения углерода легким изотопом вызвано термическим распадом органического вещества. Вероятно, в случае исследованных в настоящей работе подземных вод можно сделать предположение об участии термического распада органического вещества (а также его углефикации с высвобождением ор- ганогенной углекислоты) в формировании изотопного состава $\mathrm{C}_{\text {DIC. }}$ Однако полученные в нашем случае глубоко отрицательные значения $\delta^{13} \mathrm{C}_{\mathrm{DIC}}$ пластовых вод не типичны для термальных низкотемпературных вод. Здесь же важно подчеркнуть, что для более молодых комплексов, имеющих более отрицательные значения $\delta^{13} \mathrm{C}_{\mathrm{DIC}}$, характеры меньшие температуры вод. Последний факт явно расходится с гипотезой термического распада органического вещества: логично полагать, что с повышением температуры проявление данного механизма должно было бы усиливаться, а в нашем случае наблюдается противоположная картина - с ростом температуры водорастворенная углекислота насыщается тяжелым изотопом ${ }^{13} \mathrm{C}$. Одним из вариантов для объяснения данного феномена могут служить колонии пока что малоизученных с изотопной точки зрения термостойких археев. Так, авторам работы [50] удалось выделить из термальных грязевых источников Камчатки штамм анаэробных гипертермофильных органогетеротрофных археев, жизнеспособных в экстремальных условиях: оптимальными условиями роста штамма были температура в $92{ }^{\circ} \mathrm{C}$ при рН от 6,0 до 6,5. В работе [51] для штамма Камчатских микроорганизмов был установлен температурный интервал активного роста от 80 до $95{ }^{\circ} \mathrm{C}$ с оптимумом при $84{ }^{\circ} \mathrm{C}$. Интересно отметить, что основными продуктами биологической активности служили $\mathrm{CO}_{2}$, ацетат и $\mathrm{H}_{2}$, а при температурах 75 и $98^{\circ} \mathrm{C}$ и рН 6,2 и 8,6 роста колонии не наблюдалось. Иными словами, развитие подобных археев требует довольно узкого, но при этом экстремального для других видов микроорганизмов термального режима, а продуктами их жизнедеятельности является $\mathrm{CO}_{2}$, наследующий, по меньшей мере отчасти, изотопный состав перерабатываемого ОВ. Аналогичные термофильные микроорганизмы были обнаружены при отборе устьевой пробы в скважине из отложений юрского возраста в Парабельском районе Томской области [52], способные расщеплять целлюлозу и ее производные и развиваться как в аэробных, так и в анаэробных условиях.

Экстраполируя вышеизложенные данные на исследованные в настоящей работе подземные воды, можно предположить наличие колоний подобных термофильных микроорганизмов и в нашем случае. В пользу этой гипотезы свидетельствует то, что наиболее отрицательные значения $\delta^{13} \mathrm{C}_{\mathrm{DIC}}$ характерны для вод, имеющих условия, очень близкие к благоприятным для проживания вышеуказанных археев (таблица): во всех изученных водах значения $\mathrm{pH}$ относятся к благоприятному диапазону, а температуры не превышают $90{ }^{\circ} \mathrm{C}$. Для вод, температура которых превышает $90{ }^{\circ} \mathrm{C}$, наблюдается явное утяжеление изотопного состава $\mathrm{C}_{\text {DIC }}$ до величин, отвечающих «нормальным» значениям $\delta^{13} \mathrm{C}_{\text {DIC }}$ в термальных водах: от -8 до $+4 \%$ VPDB. Ряд отклоняющихся от общей корреляции точек (рис. 2, б, красный эллипс), повидимому, обусловлен разбавлением и/или смешением вод различных водоносных горизонтов и изменением термических условий, способных оказать влия- 
ние на жизнедеятельность гипотетических колоний термофильных археев. Тем не менее наличие термофильных микроорганизмов в изученных подземных водах носит на данный момент гипотетический характер и требует дополнительных исследований с привлечением соответствующих специалистов - микробиологов.

\section{Изотопы стронция}

Изотопные отношения стронция являются показательным трассером важных гидрогеологических процессов, таких как WRI и выявление разгрузки подземных вод в активных разломах [53]. Отношения ${ }^{87} \mathrm{Sr} /{ }^{86} \mathrm{Sr}$ вод изменяются в соответствии с вариацией отношения ${ }^{87} \mathrm{Rb} /{ }^{86} \mathrm{Sr}$ и возраста дренируемого водоносного комплекса. При этом такие природные процессы, как растворение и осаждение, не фракционируют изотопы стронция [54]. Обогащение отношения ${ }^{87} \mathrm{Sr} /{ }^{86} \mathrm{Sr}$ радиогенным изотопом ${ }^{87} \mathrm{Sr}$ происходило с течением времени при радиоактивном распаде ${ }^{87} \mathrm{Rb}$ Исходное соотношение ${ }^{87} \mathrm{Sr} /{ }^{86} \mathrm{Sr}$ на момент аккреции Земли составляло 0,69897 [55] и постепенно нарастало до современных значений. Источником радиогенного ${ }^{87} \mathrm{Sr}$ в подземных водах могут служить как воды палеоокеана, характеризующиеся определенным соотношением ${ }^{87} \mathrm{Rb} /{ }^{86} \mathrm{Sr}$ [56], так и рубидий, попадающий в воды из окружающих пород в ходе процессов выветривания $[57,58]$. В свою очередь, соотношение изотопов стронция в океанической воде в геологической шкале времени определялось балансом двух источников: 1 - обогащение вод изотопом ${ }^{87} \mathrm{Sr}$ при континентальном выветривании пород, обогащенных как ${ }^{87} \mathrm{Rb}$, так и дочерним ${ }^{87} \mathrm{Sr} ; 2$ - обеднение соотношения ${ }^{87} \mathrm{Sr} /{ }^{86} \mathrm{Sr}$ тяжелым изотопом ${ }^{87} \mathrm{Sr}$ при гидротермальном обмене в срединноокеанических хребтах и гидротермальных альтерациях подводных базальтов, породы которых имеют более низкие значения отношений ${ }^{87} \mathrm{Sr} /{ }^{86} \mathrm{Sr}$ [59]. Выветриваемый материал континентальных пород вымывался временными водотоками, обогащая воды тяжелым изотопом ${ }^{87} \mathrm{Sr}$. С изменением климатических условий варьировали интенсивности таких процессов, как оледенение, образование осадков, формирование водных потоков и выветривание пород. Это приводило, в свою очередь, к изменению интенсивности притока поверхностных вод, обогащенных изотопом ${ }^{87} \mathrm{Sr}$, к водам мирового океана и, соответственно, изменению отношения ${ }^{87} \mathrm{Sr} /{ }^{86} \mathrm{Sr}$ морской воды с течением времени. Немаловажное влияние на процесс изменения стронциевых отношений при химическом выветривании оказали тектонические процессы объединения и разрушения суперконтинента и формирование обширных базальтовых провинций [58]. Сочетание вышеописанных процессов приводило к широкому варьированию изотопного соотношения ${ }^{87} \mathrm{Sr} /{ }^{86} \mathrm{Sr}$ мирового океана, приводящее к тому, что морские воды ряда геологических периодов и эпох имеют очень близкие значения стронциевых отношений. Например, современные воды мирового океана, имеющие ${ }^{87} \mathrm{Sr} /{ }^{86} \mathrm{Sr} \sim 0,7091$, очень близки по этому параметру к водам кембрийского палеоокеана [56]. Формирование земной коры, как правило, со- провождается широким спектром пересеченных и наложенных друг на друга геологических процессов тектонических, магматических, метаморфических, приводящих к сложно-интерпретируемым запутанным системам. Тем не менее общая закономерность такова, что более древние породы в среднем обладают более высокими значениями изотопного отношения ${ }^{87} \mathrm{Sr} /{ }^{86} \mathrm{Sr}$ [60]. Выветривание подобных сложных систем приводит к еще более неоднозначному дисбалансу в соотношениях изотопов стронция. Поэтому при интерпретации изотопии стронция в водах авторы зачастую делают выводы не о возрасте вод, а об источниках, сформировавших анализируемый изотопный состав отношений ${ }^{87} \mathrm{Rb} /{ }^{86} \mathrm{Sr}$ и ${ }^{87} \mathrm{Sr} /{ }^{86} \mathrm{Sr}[54,57-62]$, иными словами, выводы относительно взаимодействия в системе «вода - горная порода».

В таблице и на рис. 3, а представлены данные по изотопным отношениям ${ }^{87} \mathrm{Rb} /{ }^{86} \mathrm{Sr}$ и ${ }^{87} \mathrm{Sr} /{ }^{86} \mathrm{Sr}$ для части исследованных вод. Выборка была сделана для вод предпочтительно разновозрастных комплексов. Из представленных данных видно, что для всех исследованных вод соотношение ${ }^{87} \mathrm{Sr} /{ }^{86} \mathrm{Sr}$ находится ниже уровня вод современного океана (рис. 3, а, оранжевая линия). По-видимому, это указывает на отсутствие инфильтрационного питания обогащенных тяжелым изотопом ${ }^{87} \mathrm{Sr}$ вод, величина ${ }^{87} \mathrm{Sr} /{ }^{86} \mathrm{Sr}$ которых, как правило, варьирует от 0,7116 до 0,7119 [58, 62]. Вероятно, это может служить аргументом в пользу положения об изолированности исследуемых вод от внешних метеорных источников. Более того, величины изотопного отношения ${ }^{87} \mathrm{Sr} /{ }^{86} \mathrm{Sr}$ большинства исследованных вод имеют очень низкие значения. Разумеется, необходимо принимать во внимание тот факт, что на момент захоронения вод стронциевые изотопные отношения могли и должны были существенно отличаться от современных. Согласно [56], колебания ${ }^{87} \mathrm{Sr} /{ }^{86} \mathrm{Sr}$ вод в период 300-66 млн лет происходило в диапазоне 0,7068-0,7081 (рис. 3, б). При условии отсутствия внешних источников ${ }^{87} \mathrm{Rb}$ воды должны были постепенно обогащаться изотопом ${ }^{87} \mathrm{Sr}$ в ходе радиоактивного распада растворенного в воде рубидия и отношение ${ }^{87} \mathrm{Sr} /{ }^{86} \mathrm{Sr}$ захороненных вод должно было постепенно увеличиваться. Сложно точно оценить величину такого прироста, поскольку точный возраст захороненных вод, равно как и их исходный состав ${ }^{87} \mathrm{Sr} /{ }^{86} \mathrm{Sr}$ и ${ }^{87} \mathrm{Rb} /{ }^{86} \mathrm{Sr}$, неизвестны. Тем не менее логично ожидать некоторое увеличение значений относительно указанных рамок 0,7068-0,7081. Из представленных данных видно, что большая часть значений стронциевых отношений находится не только внутри этих рамок, но в некоторых случаях даже меньше нижней границы - 0,7068. Вероятным объяснением этого явления может служить обогащение вод стронцием из мантийного (не радиогенного) источника, современное отношение ${ }^{87} \mathrm{Sr} /{ }^{86} \mathrm{Sr}$ в котором составляет 0,704 [59]. В результате смешения стронция исходных захороненных вод с мантийным источником гипотетический прирост отношения ${ }^{87} \mathrm{Sr} /{ }^{86} \mathrm{Sr}$ относительно диапазона 0,7068-0,7081 был, по-видимому, нивелирован, а в большинстве случаев оказался отрицательным. 

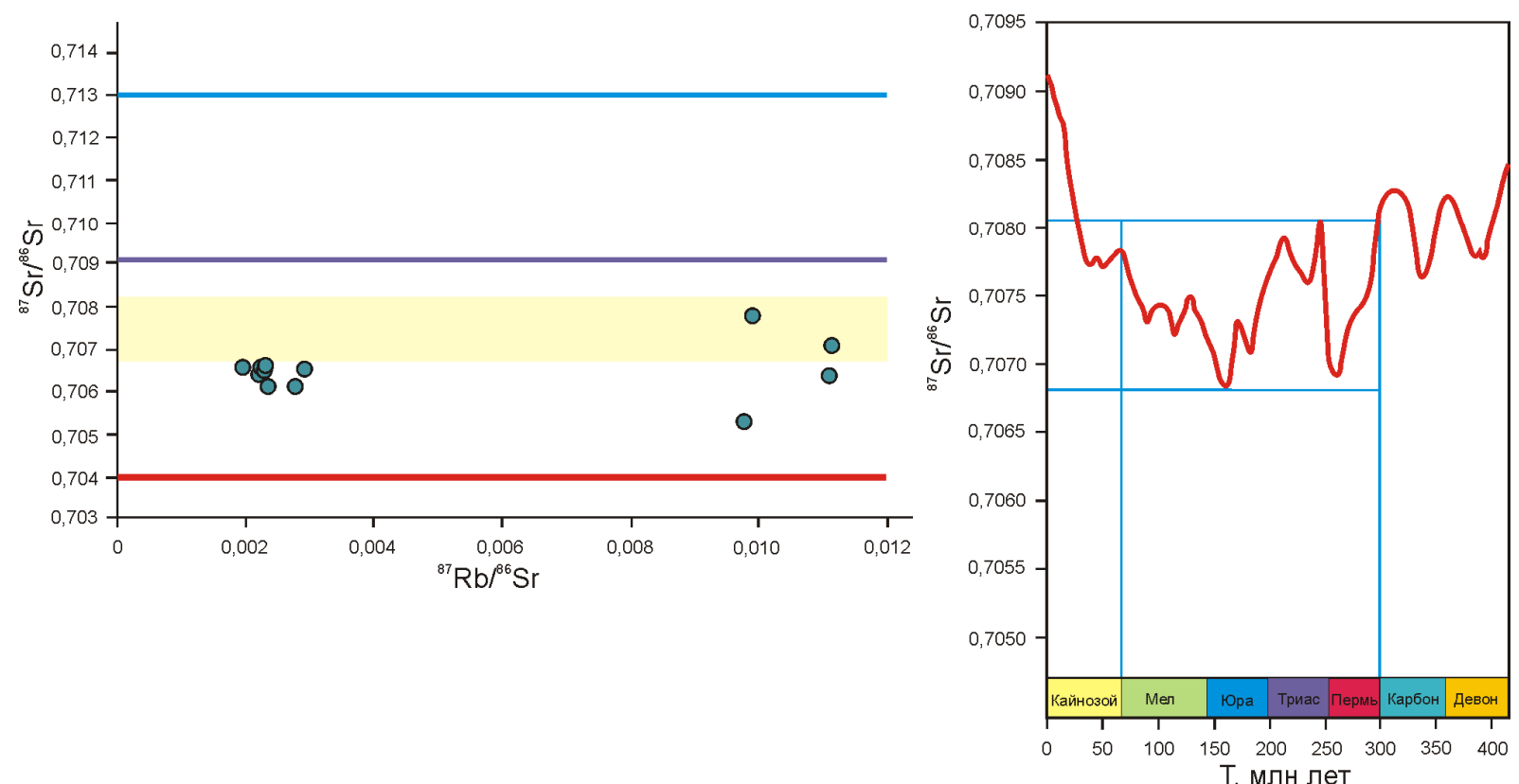

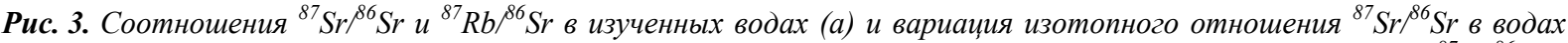
мирового океана с течением времени (б) (по [56]). Фиолетовая линия - изотопное соотношение ${ }^{87} \mathrm{Sr}{ }^{86} \mathrm{Sr} 8$ водах современного океана [56]; красная линия $-{ }^{87} \mathrm{Sr}{ }^{86} \mathrm{Sr}$ в мантийном источнике [59]; синяя линия ${ }^{87} \mathrm{Sr}{ }^{86} \mathrm{Sr}$ в современной Земной коре [59]. Желтым выделена область значений ${ }^{87} \mathrm{Sr}{ }^{86} \mathrm{Sr}$, соответствующих водам мирового океана в период 300-66 млн лет [56]

Fig. 3. ${ }^{87} \mathrm{Sr}{ }^{86} \mathrm{Sr}$ and ${ }^{87} \mathrm{Rb}{ }^{86} \mathrm{Sr}$ ratios in the studied waters (a) and variation of the ${ }^{87} \mathrm{Sr}{ }^{86} \mathrm{Sr}$ isotopic ratio in the waters of the World Ocean (b) (according to [56]). The purple line is the ${ }^{87} \mathrm{Sr}{ }^{86} \mathrm{Sr}$ isotope ratio in the waters of the modern ocean [56]; red line $-{ }^{87} \mathrm{Sr}{ }^{86} \mathrm{Sr}$ in the mantle source [59]; blue line $-{ }^{87} \mathrm{Sr}{ }^{86} \mathrm{Sr}$ in the modern Earth's crust [59]. The range of ${ }^{87} \mathrm{Sr}{ }^{86} \mathrm{Sr}$ values corresponding to the waters of the world ocean in the period 300-66 Ma is highlighted in yellow [56]

Изученные воды характеризуются еще одной интересной особенностью. Из рис. 3, $а$ видно, что все они условно подразделены на две группы: 1) с высоким содержанием ${ }^{87} \mathrm{Rb}$ (воды неокомского комплекса Северо-Кеумского и Юганского месторождений, воды нижне-среднеюрского комплекса ЗападноГерасимовского месторождения и палеозойские воды Малоичского месторождения); 2) с низким содержанием радиоактивного изотопа ${ }^{87} \mathrm{Rb}$ (остальные). Вероятно, для вод с высоким содержанием ${ }^{87} \mathrm{Rb}$ на момент захоронения произошло накопление материала выветривания, обогащенного рубидием. В дальнейшем, в ходе радиоактивного распада, воды насыщались тяжелым изотопом ${ }^{87} \mathrm{Sr}$, что наглядно иллюстрируется образцами Малоичского и Северо-Кеумского месторождений. В случае вод Юганского и ЗападноГерасимовского месторождений влияние мантийного источника стронция оказалось, по-видимому, столь существенным, что полностью подавило обогащение вод изотопом ${ }^{87} \mathrm{Sr}$, высвобождающимся при распаде ${ }^{87} \mathrm{Rb}$. Воды разрабатываемых залежей горизонта $Ю_{1}$ Верх-Тарского и Восточно-Тарского месторождений за счет процессов смешения с агентом заводнения во многом унаследовали изотопный состав стронциевых отношений апт-альб-сеноманских вод.

\section{Заключение}

Резюмируя вышесказанное, можно сделать следующие выводы:
1. Для вод изученного региона характерна довольно узкая вариация значений $\delta \mathrm{D}$ (от $-77,9 \%$ до $61,7 \%$ ) и $\delta^{18} \mathrm{O}($ от $-9,0 \%$ до $-5,1 \%$ ). Анализ данных показал, что для большинства исследованных вод пара $\delta \mathrm{D}-\delta^{18} \mathrm{O}$ располагается значительно ниже глобальной линии метеорных вод, что говорит о наличии в гидрогеологическом разрезе двух основных генетических типов подземных вод: древних инфильтрогенных и седиментогенных $[63,64]$. Величина изотопного сдвига О достигает от $+1,5 \%$ до $+(8,28-8,55) \%$. Наиболее достоверным объяснением подобных аномальных проявлений изотопного состава представляется сочетание двух влияющих факторов: исходное обеднение вод легким изотопом ${ }^{16} \mathrm{O}$ в период «до захоронения» на величину до 4-5 \% в результате климатического воздействия; дальнейшее насыщение вод тяжелым изотопом ${ }^{18} \mathrm{O}$ в ходе длительного WRI, приведшее к утяжелению изотопного состава при умеренных условиях на дополнительные 2-3\%.

2. Концентрации углерода-13 в DIC исследованных вод находятся в довольно широком интервале значений и колеблются от $-21,6$ до $+3,1 \%$. Установлено закономерное обогащение значений $\delta^{13} \mathrm{C}_{\text {DIC }}$ тяжелым изотопом ${ }^{13} \mathrm{C}$ при переходе от вод молодых комплексов к более древним. Предполагается наличие в изученных водах колоний термофильных микроорганизмов, приводящее к легкому изотопному составу углерода DIC при 
переработке ОВ. Для вод, температура которых превышает $90{ }^{\circ} \mathrm{C}$, наблюдается явное утяжеление изотопного состава $\delta^{13} \mathrm{C}_{\mathrm{DIC}}$ до величин, отвечающих «нормальным» значениям $\delta^{13} \mathrm{C}_{\mathrm{DIC}}$ в термальных водах: от -8 до $+4 \%$ VPDB.

3. Совместный анализ изотопных отношений ${ }^{87} \mathrm{Sr} /{ }^{86} \mathrm{Sr}$ и ${ }^{87} \mathrm{Rb} /{ }^{86} \mathrm{Sr}$ изученных вод указывает на то, что захоронение вод происходило как минимум двумя большими группами. Первая группа вод оказалась максимально изолированной от внешних источников радиоактивного ${ }^{87} \mathrm{Rb}$ и в ходе WRI в первую очередь обогащалась стронцием из мантийных источников. Вторая группа вод была захоронена в присутствии обильного количества материала выветривания континентальной коры, богатого радиоактивным ${ }^{87} \mathrm{Rb}$. За период захоронения в ходе WRI происходило обогащение вод

\section{СПИСОК ЛИТЕРАТУРЫ}

1. Ферронский В.И., Поляков В.А. Изотопия гидросферы. - М.: Научный мир, 2009. - 632 с

2. Нефтегазоносность верхней части палеозоя юго-востока Западно-Сибирской плиты / В.И. Биджаков, Е.Е. Даненберг, И.А. Иванов, Г.И. Тищенко // Нефтегазоносность Сибири и Дальнего Востока. - Новосибирск: СО РАН, 1981. - С. 116-121.

3. Геологические условия нефтегазоносности верхней части палеозойского разреза Западной Сибири (на примере Межовского срединного массива) / А.Э. Конторович, И.А. Иванов, А.Е. Ковешников, В.И. Краснов, Г.Н. Перозио // Теоретические и региональные проблемы геологии нефти и газа. - Новосибирск: СО РАН, 1991. - С. 152-171.

4. Contemporary development state of reservoir Yul, the VerkhTarskoe oilfield (south of Western Siberia) / Novikov D.A. Pavlova S.A., Yu Kuznetsov D., Ryzhkova S.V., Chernikov A.A. // Journal of Physics: Conference Series. - 2020. - V. 1451 (1). 012008 .

5. Месторождения (разрабатываемые). URL: https://www.novng. ru/production/deposits/ (дата обращения 10.08.2020).

6. О геотермической зональности нефтегазоносных отложений северо-западных районов Новосибирской области / Д.А. Новиков, С.В. Рыжкова, Ф.Ф. Дульцев, А.В. Черных // Известия Вузов. Нефть и газ. - 2018. - № 5. - С. 69-76.

7. Нефтегазовая гидрогеохимия доюрских комплексов южных районов Обь-Иртышского междуречья / Д.А. Новиков, С.В. Рыжкова, Ф.Ф. Дульцев, А.В. Черных, К.В. Сесь, Н.А. Ефимцев, А.Е. Шохин // Известия Томского политехнического университета. Инжиниринг георесурсов. - 2018. T. 329. - № 12. - С. 39-54.

8. Гидродинамические особенности нефтегазоносных отложений южных районов Обь-Иртышского междуречья / Д.А. Новиков, Ф.Ф. Дульцев, А.В. Черных, С.В. Рыжкова // Георесурсы. - 2019. - Т. 21. - № 4. - С. 85-94.

9. Геохимия водорастворенных газов нефтегазоносных отложений южных районов Обь-Иртышского междуречья / Д.А. Новиков, А.Е. Шохин, А.А. Черников, Ф.Ф. Дульцев, А.В. Черных // Известия Вузов. Нефть и газ. - 2019. - № 4 (136). C. $70-81$.

10. Прогноз нефтегазоносности юрских и палеозойских отложений южных районов Западно-Сибирского бассейна / Я.В. Садыкова, М.А. Фомин, С.В. Рыжкова, Д.А. Новиков, Ф.Ф. Дульцев, А.В. Черных // Известия Томского политехнического университета. Инжиниринг георесурсов. - 2019. T. 330. - № 9. - С. 114-127.

11. Stable water isotope modeling reveals spatio-temporal variability of glacier meltwater contributions to Ganges River headwaters / S. Boral, I.S. Sen, D. Ghosal, B. Peucker-Ehrenbrink, J.D Hemingway // Journal of Hydrology. - 2019. - V. 577. - 123983.

12. Swetha T.V., Gopinath G., Resmi T.R. Isotope mass balance estimation of groundwater recharge in a hard rock tropical river рубидием ${ }^{87} \mathrm{Rb}$ и его дочерним изотопом ${ }^{87} \mathrm{Sr}$. Для всех вод характерно низкое значение отношения ${ }^{87} \mathrm{Sr} /{ }^{86} \mathrm{Sr}$ относительно вод современного океана, что указывает на значительный вклад мантийных источников стронция, проявляющегося, тем не менее, в разной степени для вод различных месторождений. За счет процессов смешения с агентом заводнения воды разрабатываемых залежей горизонта Ю $Ю_{1}$ Верх-Тарского и Восточно-Тарского месторождений во многом унаследовали изотопный состав стронциевых отношений апт-альбсеноманских вод.

Исследование выполнено при финансовой поддержке проекта ФНИ № 0331-2019-0025 и проекта Российского фонда фундаментальных исследований и Правительства Новосибирской области № 19-45-540006.

basin in Kerala, India // Groundwater for Sustainable Development -2020. - V. 11. - 100422.

13. Wenninger J., Beza D.T., Uhlenbrook S. Experimental investigations of water fluxes within the soil-vegetationatmosphere system: Stable isotope mass-balance approach to partition evaporation and transpiration // Physics and Chemistry of the Earth. - 2010. - V. 35. - P. 565-570.

14. Sources and sinks of dissolved inorganic carbon in an urban tropical coastalbay revealed by $\delta^{13} \mathrm{C}$-DIC signals / L.C. Cotovicz Jr., B.A. Knoppers, L. Deirmendjian, G. Abril // Estuarine, Coastal and Shelf Science. - 2019. - V. 220. - P. 185-195.

15. Specifying recharge zones and mechanisms of the transitional geothermal field through hydrogen and oxygen isotope analyses with consideration of water-rock interaction / R.M. Shoedarto, Y. Tada, K. Kashiwaya, K. Koike // Geothermics. - 2020. - V. 86. 101797.

16. Isotope $\left(\delta \mathrm{D}, \delta^{18} \mathrm{O},{ }^{3} \mathrm{H}, \delta^{13} \mathrm{C},{ }^{14} \mathrm{C}\right)$ and chemical $(\mathrm{B}, \mathrm{Cl})$ Constrains on water origin, mixing, water-rock interaction and age of lowtemperature geothermal water / A. Stefánsson, S. Arnórsson, A.E. Sveinbjörnsdóttir, J. Heinemaier, H. Kristmannsdóttir // Applied Geochemistry. - 2019. - V. 108. - 104380.

17. Aydin H., Karakuş H., Mutlu H. Hydrogeochemistry of geothermal waters in eastern Turkey: Geochemical and isotopic constraints on water-rock interaction // Journal of Volcanology and Geothermal Research. - 2020. - V. 390.- 106708.

18. Craig H. Isotopic variations in meteoric waters // Science. 1961. - V. 133. - P. 1702-1703.

19. Influence of rainfall quantity on the isotopic composition (18O and $2 \mathrm{H})$ of water in mountainous areas. Application for groundwater research in the Yunquera-Nieves karst aquifers (S Spain) / B. Andreo, C. Linan, F. Carrasco, C. Jimenez de Cisneros, F. Caballero, J. Mudry // Applied Geochemistry. - 2004. - V. 19. P. 561-574.

20. Shemelina O., Sanchaa A., Faguet A. Isotopic characteristics $\left(\delta^{18} \mathrm{O}\right.$ and $\delta \mathrm{D}$ ) of surface and groundwater as an additional tool for searching quality drinking water (Western part of Novosibirsk Region, Russia) // E3S Web of Conferences. - 2019. - V. 98. 012019 .

21. Chemo-isotopes $(18 \mathrm{O} \& 2 \mathrm{H})$ signatures and HYSPLIT model application: clues to the atmospheric moisture and air mass origins / R. Bagheri, F. Bagheri, G.H. Karami, H. Jafari // Atmospheric Environment. - 2019. - V. 215. - 116892.

22. Hydrochemical and isotopic characterization of groundwater in the Ghis-Nekor plain (northern Morocco) / D. Chafouq, A.El. Mandour, M. Elgettafi, M. Himi, I. Chouikri, A. Casas // Journal of African Earth Sciences. - 2018. - V. 139. - P. 1-13.

23. Spatial distribution and controlling factors of surface water stable isotope values $\left(\delta^{18} \mathrm{O}\right.$ and $\left.\delta^{2} \mathrm{H}\right)$ across Kazakhstan, Central Asia / H. Wu, J. Wu, F. Song, J. Abuduwaili, A.S. Saparov, X. Chen, B. Shen // Science of the Total Environment. - 2019. - V. 678. P. 53-61. 
24. Nicholson K. Geothermal fluids, chemistry and exploration techniques. - Berlin; Heidelberg: Springer-Verlag Publ., 1993. $223 \mathrm{p}$.

25. Палеогеография Западно-Сибирского осадочного бассейна в меловом периоде / А.Э. Конторович, С.В. Ершов, В.А. Казаненков, Ю.Н. Карогодин, В.А. Конторович, Н.К. Лебедева, Б.Л. Никитенко, Н.И. Попова, Б.Н. Шурыгин // Геология и геофизика. - 2014. - Т. 55. - № 5-6. - С. 745-776.

26. Carbon sequestration in an expanded lake system during the Toarcian oceanic anoxic event / W. Xu, M. Ruhl, H.C. Jenkyns, S.P. Hesselbo, J.B. Riding, D. Selby, B.D.A. Naafs, J.W.H. Weijers, R.D. Pancost, E.W. Tegelaar, E.F. Idiz // Nature Geoscience. - 2017. - V. 10. - P. 129-135.

27. Jurassic paleogeography of the Tian Shan: an evolution driven by far-field tectonics and climate / J. Morin, M. Jolivet, C. Robin, G. Heilbronn, L. Barrier, S. Bourquin, Y. Jia // Earth-Science Reviews. - 2018. - V. 187. - P. 286-313.

28. The climate change caused by the land plant invasion in the Devonian / G.L. Hir, Y. Donnadieu, Y. Godderis, B. MeyerBerthaud, G. Ramstein, R.C. Blakey // Earth and Planetary Science Letters. - 2011. - V. 310. - P. 203-212.

29. Huang C., Joachimski M.M., Gong Y. Did climate changes trigger the Late Devonian Kellwasser Crisis? Evidence from a highresolution conodont $\delta 18 \mathrm{OPO} 4$ record from South China // Earth and Planetary Science Letters. - 2018. - V. 495. - P. 174-184.

30. CO2 as a primary driver of Phanerozoic climate / D.L. Royer, R.A. Berner, I.P. Montanez, N.J. Tabor, D.J. Beerling // Geological Society of America Today. - 2004. - V. 14. - № 3. - P 4-10.

31. Das A., Krishnaswami S., Bhattacharya S.K. Carbon isotope ratio of dissolved inorganic carbon (DIC) in rivers draining the Deccan Traps, India: Sources of DIC and their magnitudes // Earth and Planetary Science Letters. - 2005. - V. 236. - Iss. 1-2. - P. 419-429.

32. Liu Z., Dreybrodt W., Wang H. A new direction in effective accounting for the atmospheric $\mathrm{CO} 2$ budget: considering the combined action of carbonate dissolution, the global water cycle and photosynthetic uptake of DIC by aquatic organisms // EarthScience Reviews. - 2010. - V. 99. - № 3-4. - P. 162-172.

33. Carbon isotope signature of dissolved inorganic carbon (DIC) in precipitation and atmospheric $\mathrm{CO}_{2} /$ M. Górka, P.E. Sauer, D. Lewicka-Szczebak, M.-O. Jędrysek // Environmental Pollution Volume. - 2011. - V. 159. - № 1. - P. 294-301.

34. Deirmendjian L., Abril G. Carbon dioxide degassing at the groundwater-stream-atmosphere interface: isotopic equilibration and hydrological mass balance in a sandy watershed // Journal of Hydrology. - 2018. - V. 558. - P. 129-143.

35. Assessing sulfate reduction and methane cycling in a high salinity pore water system in the northern Gulf of Mexico / J.W. Pohlman, C. Ruppel, D.R. Hutchinson, R. Downer, R.B. Coffin // Marine and Petroleum Geology. - 2008. - V. 25. - P. 942-951.

36. Origin of dissolved gas (CO2, O2, N2, alkanes) in pore waters of a clay formation in the critical zone (Tegulines Clay, France) / C. Lerouge, M. Debure, B. Henry, A.-M. Fernandez, M. Blessing, E. Proust, B. Made, J.-C. Robinet // Applied Geochemistry. 2020. - V. 116. - 104573.

37. Variations of soil $\mathrm{CO} 2$ concentration and $p \mathrm{CO} 2$ in a cave stream on different time scales in subtropical climatic regime / M. Cao, Y. Jiang, Y. Chen, J. Fan, Q. He // Catena. - 2020. - V. 185. 104280 .

38. Anaerobic digestion of renewable biomass: thermophilic temperature governs methanogen population dynamics / N. Krakat A. Westphal, S. Schmidt, P. Scherer // Applied and Environmental Microbiology. - 2020. - V. 76. - Iss. 6. - P. 1842-1850.

39. Stable isotopes $\left(\delta^{13} \mathrm{C}_{\mathrm{DIC}}, \delta \mathrm{D}, \delta^{18} \mathrm{O}\right)$ and geochemical characteristics of geothermal springs of Ladakh and Himachal (India): evidence for $\mathrm{CO} 2$ discharge in northwest Himalaya / S.K. Tiwari, S.K. Rai, S.K. Bartarya, A.K. Gupta, M. Negi // Geothermics. - 2016. V. 64. - P. 314-330.

40. Tiwari S.K., Gupta A.K., Asthana A.K.L. Evaluating CO2 flux and recharge source in geothermal springs, Garhwal Himalaya, India: stable isotope systematics and geochemical proxies // Environmental Science and Pollution Research. - 2020. - V. 27. P. 14818-14835.

41. Friedman I. Some investigations of the deposition of travertine from Hot Springs - I. The isotopic chemistry of a travertine- depositing spring // Geochimica et Cosmochimica Acta. - 1970. V. 34. - Iss. 12. - P. 1303-1315.

42. Stable isotope characterisation of recent aragonite travertine deposits associated with the Fitero thermal waters (Spain) / M. Blasco, L.F. Auqué, M.J. Gimeno, M.P. Asta, J. Mandado // International Journal of Earth Sciences. - 2020. - V. 109. - Iss. 3. - P. 877-892.

43. Origin and evolution of the thermal waters from the Pamukkale Geothermal Field (Denizli Basin, SW Anatolia, Turkey): insights from hydrogeochemistry and geothermometry / H. Alçiçek, A. Bülbül, İ. Yavuzer, M. Cihat Alçiçek // Journal of Volcanology and Geothermal Research. - 2019. - V. 372. - P. 48-70.

44. Chemical and stable isotope composition of recent hot-water travertines and associated thermal waters, from Egerszalók, Hungary: depositional facies and non-equilibrium fractionation / S. Kele, A. Demény, Z. Siklósy, T. Németh, M. Tóth, M.B. Kovács // Sedimentary Geology. - 2008. - V. 211. - Iss. 3-4. - P. 53-72.

45. Marty B., Jambon A. $\mathrm{C}^{3} \mathrm{He}$ in volatile fluxes from the solid Earth: implications for carbon geodynamics // Earth and Planetary Science Letters. - 1987. - V. 83. - Iss. 1-4. - P. 16-26.

46. C-He systematics in hotspot xenoliths: implications for mantle carbon contents and carbon recycling / T. Trull, S. Nadeau, F. Pineau, M. Polve, M. Javoy // Earth and Planetary Science Letters. - 1993. - V. 118. - Iss. 1-4. - P. 43-64.

47. Aqueous and isotope geochemistry of mineral springs along the southern margin of the Tibetan plateau: implications for fluid sources and regional degassing of CO2 / D.L. Newell, M.J. Jessup, J.M. Cottle, D.R. Hilton, Z.D. Sharp, T.P. Fischer // Geochemistry, Geophysics, Geosystems. - 2008. - V. 9. - Iss. 8. - Q08014.

48. Evans M.J., Derry L.A., France-Lanord C. Degassing of metamorphic carbon dioxide from the Nepal Himalaya // Geochemistry, Geophysics, Geosystems. - 2008. - V. 9. - Iss. 4. Q04021.

49. Complete genomic sequence of «Thermofilum adornatus» strain 1910bT, a hyperthermophilic anaerobic organotrophic crenarchaeon / I.N. Dominova, I.V., Kublanov O.A. Podosokorskaya, K.S. Derbikova, M.V. Patrushev, S.V. Toshchakov // Genome Announcements. - 2013. - V. 1. - Iss. 5. e00726-13.

50. Thermogladius calderae gen. nov., sp. nov., an anaerobic, hyperthermophilic crenarchaeote from a Kamchatka hot spring / T.V. Kochetkova, I.V. Kublanov, S.V., Toshchakov M.R. Osburn, A.A. Novikov, E.A. Bonch-Osmolovskaya, A.A. Perevalova // International Journal of Systematic and Evolutionary Microbiology. - 2016. - V. 66. - Iss. 3. - P. 1407-1412.

51. Characterization of Melioribacter roseus gen. nov., sp. nov., a novel facultatively anaerobic thermophilic cellulolytic bacterium from the class Ignavibacteria, and a proposal of a novel bacterial phylum Ignavibacteriae / O.A. Podosokorskaya, V.V. Kadnikov, S.N. Gavrilov, A.V. Mardanov, A.Y. Merkel, O.V. Karnachuk, N.V. Ravin, E.A. Bonch-Osmolovskaya, I.V. Kublanov // Environmental Microbiology. - 2013. - V. 15. - Iss. 6. - P. 17591771.

52. New thermophilic prokaryotes with hydrolytic activities / E. BonchOsmolovskaya, A. Elcheninov, K. Zayulina, I. Kublanov // Microbiology Australia. - 2018. - V. 39. - Iss. 3. - P. 122-125.

53. $87 \mathrm{Sr} / 86 \mathrm{Sr}$ ratios in shallow and deep aquifers and thermal water from the eastern boundary fault of the Northern Upper Rhine Graben at the Heidelberg Basin, Germany / G. Schmidt, S.A. Najem, M. Isenbeck-Schröter, F. Freundt, M. Kraml, R. Eichstadter, W. Aeschbach // Procedia Earth and Planetary Science. - 2017. - V. 17. - P. 108-111.

54. Petelet-Giraud E., Négrel P., Casanova J. Tracing mixings and water-rock interactions in the Loire River Basin (France): $\delta 180$ $\delta 2 \mathrm{H}$ and $87 \mathrm{Sr} / 86 \mathrm{Sr} / /$ Procedia Earth and Planetary Science. 2017. - V. 17. - P. 794-797.

55. Hans U., Kleine T., Bourdon B. Rb-Sr chronology of volatile depletion in differentiated protoplanets: BABI, ADOR and ALL revisited // Earth and Planetary Science Letters. - 2013. - V. 374. - P. 204-214.

56. McArthur J.M., Howarth R.J., Shields G.A. The Geologic Time Scale. Chapter 7 - Strontium Isotope Stratigraphy. - Amsterdam: Elsiver, 2012. - P. 127-144. 
57. Alexeev S., Alexeeva L., Shouakar-Stash O. Strontium isotopic ratio in brines from the north-east of the Angara-Lenskiy artesian basin // E3S Web of Conferences. - 2019. - V. 98. - 12001.

58. Sr isotopic characteristics and fractionation during weathering of a small granitic watershed system in the Jiuhua Mountains (eastern China) / W. Weihua, S. Mingzhao, J. Xiang, Q. Shuyi // Journal of Hydrology. - 2019. - V. 568. - P. 135-146.

59. Korte C., Ullmann C.V. Permian strontium isotope stratigraphy // Geological Society London Special Publications. - 2016. V. 450 . - Iss. 1. - P. 105-118.

60. Banner J.L. Radiogenic isotopes: systematics and applications to earth surface processes and chemical stratigraphy // Earth-Science Reviews. - 2004. - V. 65. - Iss. 3-4. - P. 141-194.

61. Armstrong S.C., Sturchio N.C., Hendry M.J. Strontium isotopic evidence on the chemical evolution of pore waters in the Milk
River aquifer, Alberta, Canada // Applied Geochemistry. - 1998. V. 13. - P. 463-475

62. Tracking multiple $\mathrm{Sr}$ sources through variations in $87 \mathrm{Sr} / 86 \mathrm{Sr}$ ratios of surface waters from the Aljustrel massive sulphide mining area: Geological versus anthropogenic inputs / A.T. Luis, N. Duraes, E. Ferreira da Silva, S. Ribeiro, A.J.F. Silva, C. Patinha, S.F.P. Almeida, M.R. Azevedo // Applied Geochemistry. - 2019. V. 102. - P. $108-120$.

63. Novikov D.A. Hydrogeochemistry of the Arctic areas of Siberian petroleum basins // Petroleum Exploration and Development. 2017. - V. 44. - № 5. - P. 780-786

64. Novikov D.A. Genetic classification of subsurface waters and brines of Arctic regions of Siberia // IOP Conference Series: Earth and Environmental Science. - 2018. - V. 193. - 012049.

Поступила 30.08.2020 г.

\section{Информация об авторах}

Новиков Д.А., кандидат геолого-минералогических наук, заведующий лабораторией гидрогеологии осадочных бассейнов Сибири Института нефтегазовой геологии и геофизики им. А.А. Трофимука СО РАН; доцент кафедры геологии месторождений нефти и газа и кафедры общей и региональной геологии Новосибирского национального исследовательского государственного университета.

Пыряев А.Н., кандидат химических наук, научный сотрудник лаборатории изотопно-аналитической геохимии Института геологии и минералогии им. В.С. Соболева СО РАН; ассистент кафедры химической и биологической физики Новосибирского национального исследовательского государственного университета.

Черных А.В., научный сотрудник лаборатории гидрогеологии осадочных бассейнов Сибири Института нефтегазовой геологии и геофизики им. А.А. Трофимука Сибирского отделения Российской академии наук.

Дульцев Ф.Ф., научный сотрудник лаборатории гидрогеологии осадочных бассейнов Сибири Института нефтегазовой геологии и геофизики им. А.А. Трофимука Сибирского отделения Российской академии наук.

Рыжкова С.B., кандидат геолого-минералогических наук, старший научный сотрудник лаборатории проблем геологии, разведки и разработки месторождений трудноизвлекаемой нефти Института нефтегазовой геологии и геофизики им. А.А. Трофимука Сибирского отделения Российской академии наук; доцент кафедры геологии месторождений нефти и газа Новосибирского национального исследовательского государственного университета. 
UDK $556.314(571 / 5)$

\section{THE FIRST DATA ON THE ISOTOPIC COMPOSITION OF STRATAL WATERS OF THE DEVELOPED OIL FIELDS IN NOVOSIBIRSK REGION}

Dmitry A. Novikov1,2, NovikovDA@ipgg.sbras.ru

\section{Aleksandr N. Pyrayev3,2,} pyrayev@igm.nsc.ru

Anatoliy V. Chernykh ${ }^{1}$, ChernykhAV@ipgg.sbras.ru

Fedor F. Dultsev'1, DultsevFF@ipgg.sbras.ru

Svetlana V. Ryzhkova ${ }^{1,2}$, RizhkovaSV@ipgg.sbras.ru

1 Trofimuk Institute of Petroleum Geology and Geophysics of SB of RAS, 3/6, Koptyug avenue, Novosibirsk, 630090, Russia.

2 Novosibirsk State University, 1, Pirogov street, Novosibirsk, 630090, Russia.

3 Institute of Geology and Mineralogy of SB RAS,

3 , Koptyug avenue, Novosibirsk, 630090, Russia.

The relevance of the research lies in solving the issues of isotope geochemistry of groundwater in oil and gas deposits of large artesian basins. The waters of oil and gas bearing sediments of the region under consideration are practically not studied from the point of view of the distribution of stable isotopes $\delta D, \delta^{18} \mathrm{O}, \delta^{13} \mathrm{C}$ and isotopic ratios ${ }^{87} \mathrm{Sr} 86 / \mathrm{Sr}$ and ${ }^{87} \mathrm{Rb} /{ }^{86} \mathrm{Sr}$.

The aim of the research is to identify the features of the genesis of groundwater and the interaction in the «water-rock» system from the standpoint of isotopic geochemistry.

Methods. The analysis of the complex of $\delta D, \delta^{18} \mathrm{O}, \delta^{13} \mathrm{C}$ IC of waters and dissolved inorganic carbon was carried out at the Center for Collective Use of the IGM SB RAS using the Isotope Ratio Mass Spectrometer FinniganTM MAT 253. The ${ }^{87} \mathrm{Sr}{ }^{86} / \mathrm{Sr} u^{87} \mathrm{Rb} /{ }^{86} \mathrm{Sr}$ isotopic ratios were studied on an MI 1201T mass spectrometer in a two-tape mode with registration on one collector.

Results. The authors have studied the stable isotope composition $\left(\delta D, \delta^{18} \mathrm{O}, \delta^{13} \mathrm{CDIC}\right.$ ) and isotopic ratios of ${ }^{87} \mathrm{Sr}{ }^{86} / \mathrm{Sr}$ and ${ }^{87} \mathrm{Rb} /{ }^{86} \mathrm{Sr}$ of the waters of the developed oil fields of the Novosibirsk region. The hydrogeological section shows the presence of two main genetic types of groundwater: ancient infiltrogenic and sedimentogenic. For most of the studied samples, the $\delta D-\delta 180$ indicates a combination of two determining factors: initial depletion of water in the light isotope ${ }^{16} \mathrm{O}$ as a result of climatic impact during the period «before disposal» up to 4-5\%; further saturation of waters with the heavy isotope ${ }^{18} \mathrm{O}$ during a long WRI, which led to additional 2-3\% of heavier isotopic composition. The $\delta^{13} C_{D I C}$ values for a number of samples suggested bacterial origin of dissolved inorganic carbon. There is a clear increase in the $\delta^{13} C_{D I C}$ in waters which temperature exceeds $90{ }^{\circ} \mathrm{C}$, to the values corresponding to the «normal» ones in thermal waters: from -8 up to $+4 \%$ VPDB. The waters are characterized by low ${ }^{87} \mathrm{Sr} 86 / \mathrm{Sr}$ ratios relative to ocean waters. A significant contribution of mantle sources of strontium is assumed, which manifests itself to different degrees for the waters of various deposits.

\section{Key words:}

Groundwater, $\delta^{18} \mathrm{O}, \delta D, \delta^{13} \mathrm{C}$, isotopic ratios of ${ }^{87} \mathrm{Sr}{ }^{86} / \mathrm{Sr} u^{87} \mathrm{Rb} /{ }^{86} \mathrm{Sr}$,

interaction in «water-rock» system, developed pool, oil field, Novosibirsk region, Western Siberia.

The research was conducted with the financial support from the Fundamental Research Program of the Russian Academy of Science, project no. 0331-2019-0025, the Russian Foundation for Basic Research, project no. 19-45-540006, and the Government of the Novosibirsk region.

\section{REFERENCES}

1. Ferronskiy V.I., Polyakov V.A. Izotopiya gidrosfery [Isotopy of the hydrosphere]. Moscow, Nauchny Mir Publ., 2009. 632 p.

2. Bidzhakov V.I., Danenberg Ye.Ye., Ivanov I.A., Tishchenko G.I. Neftegazonosnost verkhney chasti paleozoya yugo-vostoka $\mathrm{Za}$ padno-Sibirskoy plity [Oil and gas content of the upper part of the Paleozoic in the southeast of the West Siberian plate]. Neftegazonosnost Sibiri i Dalnego Vostoka [Oil and gas content of Siberia and the Far East]. Novosibirsk, SB RAS, 1981. pp. 116-121.

3. Kontorovich A.E., Ivanov I.A., Koveshnikov A.Ye., Krasnov V.I., Perozio G.N. Geologicheskiye usloviya neftegazonosnosti verkhney chasti paleozoyskogo razreza Zapadnoy Sibiri (na primere Mezhovskogo sredinnogo massiva) [Geological conditions of oil and gas content of the upper part of the Paleozoic section of Western Siberia (on the example of the Mezhovsky median massif)]. Teoreticheskiye $i$ regionalnyye problemy geologii nefti i gaza [Theoretical and regional problems of oil and gas geology]. Novosibirsk, SB RAS, 1991. pp. 152-171.

4. Novikov D.A., Pavlova S.A., Kuznetsov Yu.D., Ryzhkova S.V., Chernikov A.A. Contemporary development state of reservoir Yul, the Verkh-Tarskoe oilfield (south of Western Siberia). Journal of Physics: Conference Series, 2020, vol. 1451 (1), 012008.

5. Mestorozhdeniya (razrabatyvaemye) [Deposits (developed)]. Available at: https://www.novng.ru/production/deposits/ (accessed 10 August 2020). 
6. Novikov D.A., Ryzhkova S.V., Dultsev F.F., Chernykh A.V. On the geothermal zoning of oil and gas deposits in the northwestern regions of the Novosibirsk region. Oil and Gas Studies, 2018, no. 5, pp. 69-76. In Rus.

7. Novikov D.A., Ryzhkova S.V., Dultsev F.F., Chernykh A.V., Ses K.V., Efimtsev N.A., Shokhin A.E. Oil and gas hydrogeochemistry of pre-Jurassic complexes in the southern regions of the Ob-Irtysh interfluve. Bulletin of the Tomsk Polytechnic University. Geo Assets Engineering, 2018, vol. 329, no. 12, pp. 39-54. In Rus.

8. Novikov D.A., Dultsev F.F., Chernykh A.V., Ryzhkova S.V. Hydrodynamic features of oil and gas deposits in the southern regions of the Ob-Irtysh interfluve. Georesources, 2019, vol. 21, no. 4, pp. 85-94. In Rus.

9. Novikov D.A., Shokhin A.E., Chernikov A.A., Dultsev F.F., Chernykh A.V. Geochemistry of water-dissolved gases of oil and gas deposits in the southern regions of the Ob-Irtysh interfluve. Oil and Gas Studies, 2019, no. 4 (136), pp. 70-81. In Rus.

10. Sadykova Ya.V., Fomin M.A., Ryzhkova S.V., Novikov D.A. Dultsev F.F., Chernykh A.V. Forecast of the oil and gas content of the Jurassic and Paleozoic sediments of the southern regions of the West Siberian basin. Bulletin of the Tomsk Polytechnic University. Geo Assets Engineering, 2019, vol. 330, no. 9, pp. 114-127. In Rus.

11. Boral S., Sen I.S., Ghosal D., Peucker-Ehrenbrink B., Hemingway J.D. Stable water isotope modeling reveals spatio-temporal variability of glacier meltwater contributions to Ganges River headwaters. Journal of Hydrology, 2019, vol. 577, 123983

12. Swetha T.V., Gopinath G., Resmi T.R. Isotope mass balance estimation of groundwater recharge in a hard rock tropical river basin in Kerala, India. Groundwater for Sustainable Development, 2020 , vol. 11, 100422.

13. Wenninger J., Beza D.T., Uhlenbrook S. Experimental investigations of water fluxes within the soil-vegetation-atmosphere system: Stable isotope mass-balance approach to partition evaporation and transpiration. Physics and Chemistry of the Earth, 2010, vol. 35 , pp. $565-570$.

14. Cotovicz L.C. Jr., Knoppers B.A., Deirmendjian L., Abril G. Sources and sinks of dissolved inorganic carbon in an urban tropical coastalbay revealed by $\delta^{13} \mathrm{C}$-DIC signals. Estuarine, Coastal and Shelf Science, 2019, vol. 220, pp. 185-195.

15. Shoedarto R.M., Tada Y., Kashiwaya K., Koike K. Specifying recharge zones and mechanisms of the transitional geothermal field through hydrogen and oxygen isotope analyses with consideration of water-rock interaction. Geothermics, 2020, vol. 86, 101797.

16. Stefánsson A., Arnórsson S., Sveinbjörnsdóttir A.E., Heinemaier J, Kristmannsdóttir $\mathrm{H}$. Isotope $\left(\delta \mathrm{D}, \delta^{18} \mathrm{O},{ }^{3} \mathrm{H}, \delta{ }^{13} \mathrm{C},{ }^{14} \mathrm{C}\right)$ and chemical $(\mathrm{B}, \mathrm{Cl})$ Constrains on water origin, mixing, water-rock interaction and age of low-temperature geothermal water. Applied Geochemistry, 2019, vol. 108, 104380.

17. Aydin H., Karakuş H., Mutlu H. Hydrogeochemistry of geothermal waters in eastern Turkey: Geochemical and isotopic constraints on water-rock interaction. Journal of Volcanology and Geothermal Research, 2020, vol. 390, 106708.

18. Craig H. Isotopic variations in meteoric waters. Science, 1961, vol. 133, pp. 1702-1703.

19. Andreo B., Linan C., Carrasco F., Jimenez de Cisneros C., Caballero F., Mudry J. Influence of rainfall quantity on the isotopic composition $(18 \mathrm{O}$ and $2 \mathrm{H})$ of water in mountainous areas. Application for groundwater research in the Yunquera-Nieves karst aquifers (S Spain). Applied Geochemistry, 2004, vol. 19, pp. 561-574.

20. Shemelina O., Sanchaa A., Faguet A. Isotopic characteristics $\left(\delta^{18} O\right.$ and $\delta \mathrm{D}$ ) of surface and groundwater as an additional tool for searching quality drinking water (Western part of Novosibirsk Region, Russia). E3S Web of Conferences, 2019, vol. 98, 012019.

21. Bagheri R., Bagheri F., Karami G. H., Jafari H. Chemo-isotopes $(18 \mathrm{O} \& 2 \mathrm{H})$ signatures and HYSPLIT model application: clues to the atmospheric moisture and air mass origins. Atmospheric Environment, 2019, vol. 215, 116892

22. Chafouq D., Mandour A.El., Elgettafi M., Himi M., Chouikri I, Casas A. Hydrochemical and isotopic characterization of groundwater in the Ghis-Nekor plain (northern Morocco). Journal of African Earth Sciences, 2018, vol. 139, pp. 1-13.

23. Wu H., Wu J., Song F., Abuduwaili J., Saparov A.S., Chen X., Shen B. Spatial distribution and controlling factors of surface water stable isotope values $\left(\delta^{18} \mathrm{O}\right.$ and $\left.\delta^{2} \mathrm{H}\right)$ across Kazakhstan, Cen- tral Asia. Science of the Total Environment, 2019, vol. 678, pp. 53-61.

24. Nicholson K. Geothermal fluids, chemistry and exploration techniques. Berlin, Heidelberg, Springer-Verlag Publ., 1993. 223 p.

25. Kontorovich A.E., Ershov S.V., Kazanenkov V.A., Karogodin Yu.N., Kontorovich V.A., Lebedeva N.K., Nikitenko B.L., Popova N.I., Shurygin B.N. Paleogeography of the West Siberian sedimentary basin in the Cretaceous period. Russian Geology and Geophysics, 2014, vol. 55, no. 5-6, pp. 745-776. In Rus.

26. Xu W., Ruhl M., Jenkyns H.C., Hesselbo S.P., Riding J.B., Selby D., Naafs B.D.A., Weijers J.W.H., Pancost R.D., Tegelaar E.W., Idiz E.F. Carbon sequestration in an expanded lake system during the Toarcian oceanic anoxic event. Nature Geoscience, 2017, vol. 10, pp. 129-135.

27. Morin J., Jolivet M., Robin C., Heilbronn G., Barrier L., Bourquin S., Jia Y. Jurassic paleogeography of the Tian Shan: An evolution driven by far-field tectonics and climate. Earth-Science Reviews, 2018, vol. 187, pp. 286-313

28. Hir G.L., Donnadieu Y., Godderis Y., Meyer-Berthaud B., Ramstein G., Blakey R.C. The climate change caused by the land plant invasion in the Devonian. Earth and Planetary Science Letters, 2011, vol. 310, pp. 203-212.

29. Huang C., Joachimski M.M., Gong Y. Did climate changes trigger the Late Devonian Kellwasser Crisis? Evidence from a highresolution conodont $\delta 18 \mathrm{OPO} 4$ record from South China. Earth and Planetary Science Letters, 2018, vol. 495, pp. 174-184.

30. Royer D.L., Berner R.A., Montanez I.P., Tabor N.J., Beerling D.J. $\mathrm{CO} 2$ as a primary driver of Phanerozoic climate. Geological Society of America Today, 2004, vol. 14, no. 3, pp. 4-10.

31. Das A., Krishnaswami S., Bhattacharya S.K. Carbon isotope ratio of dissolved inorganic carbon (DIC) in rivers draining the Deccan Traps, India: sources of DIC and their magnitudes. Earth and Planetary Science Letters, 2005, vol. 236, Iss. 1-2, pp. 419-429.

32. Liu Z., Dreybrodt W., Wang H. A new direction in effective accounting for the atmospheric $\mathrm{CO} 2$ budget: Considering the combined action of carbonate dissolution, the global water cycle and photosynthetic uptake of DIC by aquatic organisms. Earth-Science Reviews, 2010, vol. 99, no. 3-4, pp. 162-172.

33. Górka M., Sauer P.E., Lewicka-Szczebak D., Jędrysek M.-O. Carbon isotope signature of dissolved inorganic carbon (DIC) in precipitation and atmospheric $\mathrm{CO}_{2}$. Environmental Pollution Volume, 2011, vol. 159, no. 1, pp. 294-301.

34. Deirmendjian L., Abril G. Carbon dioxide degassing at the groundwater-stream-atmosphere interface: isotopic equilibration and hydrological mass balance in a sandy watershed. Journal of Hydrology, 2018, vol. 558, pp. 129-143.

35. Pohlman J.W., Ruppel C., Hutchinson D.R., Downer R., Coffin R.B. Assessing sulfate reduction and methane cycling in a high salinity pore water system in the northern Gulf of Mexico. Marine and Petroleum Geology, 2008, vol. 25, pp. 942-951.

36. Lerouge C., Debure M., Henry B., Fernandez A.-M., Blessing M., Proust E., Made B., Robinet J.-C.Origin of dissolved gas ( $\mathrm{CO}$, $\mathrm{O} 2$, N2, alkanes) in pore waters of a clay formation in the critical zone (Tegulines Clay, France). Applied Geochemistry, 2020, vol. 116, 104573.

37. Cao M., Jiang Y., Chen Y., Fan J., He Q. Variations of soil CO2 concentration and $p \mathrm{CO} 2$ in a cave stream on differenttime scales in subtropical climatic regime. Catena, 2020, vol. 185, 104280.

38. Krakat N., Westphal A., Schmidt S., Scherer P. Anaerobic digestion of renewable biomass: thermophilic temperature governs methanogen population dynamics. Applied and Environmental Microbiology, 2020, vol. 76, Iss. 6, pp. 1842-1850.

39. Tiwari S.K., Rai S.K., Bartarya S.K., Gupta A.K., Negi M. Stable isotopes $\left(\delta^{13} \mathrm{C}_{\mathrm{DIC}}, \delta \mathrm{D}, \delta^{18} \mathrm{O}\right)$ and geochemical characteristics of geothermal springs of Ladakh and Himachal (India): Evidence for CO2 discharge in northwest Himalaya. Geothermics, 2016, vol. 64, pp. 314-330.

40. Tiwari S.K., Gupta A.K., Asthana A.K.L. Evaluating CO2 flux and recharge source in geothermal springs, Garhwal Himalaya, India: stable isotope systematics and geochemical proxies. Environmental Science and Pollution Research, 2020, vol. 27, pp. 14818-14835.

41. Friedman I. Some investigations of the deposition of travertine from Hot Springs - I. The isotopic chemistry of a travertinedepositing spring. Geochimica et Cosmochimica Acta, 1970, vol. 34, Iss. 12, pp. 1303-1315. 
42. Blasco M., Auqué L.F., Gimeno M.J., Asta M.P., Mandado J. Stable isotope characterisation of recent aragonite travertine deposits associated with the Fitero thermal waters (Spain). International Journal of Earth Sciences, 2020, vol. 109, Iss. 3, pp. 877-892.

43. Alçiçek H., Bülbül A., Yavuzer İ., Cihat Alçiçek M. Origin and evolution of the thermal waters from the Pamukkale Geothermal Field (Denizli Basin, SW Anatolia, Turkey): Insights from hydrogeochemistry and geothermometry. Journal of Volcanology and Geothermal Research, 2019, vol. 372, pp. 48-70.

44. Kele S., Demény A., Siklósy Z., Németh T., Tóth M., Kovács M.B. Chemical and stable isotope composition of recent hot-water travertines and associated thermal waters, from Egerszalók, Hungary: depositional facies and non-equilibrium fractionation. Sedimentary Geology, 2008, vol. 211, Iss. 3-4, pp. 53-72.

45. Marty B., Jambon A. $\mathrm{C}^{3} \mathrm{He}$ in volatile fluxes from the solid Earth implications for carbon geodynamics. Earth and Planetary Science Letters, 1987, vol. 83, Issues 1-4, pp. 16-26.

46. Trull T., Nadeau S., Pineau F., Polve M., Javoy M. C-He systematics in hotspot xenoliths: implications for mantle carbon contents and carbon recycling. Earth and Planetary Science Letters, 1993, vol. 118, Iss. 1-4, pp. 43-64.

47. Newell D.L., Jessup M.J., Cottle J.M., Hilton D.R., Sharp Z.D., Fischer T.P. Aqueous and isotope geochemistry of mineral springs along the southern margin of the Tibetan plateau: Implications for fluid sources and regional degassing of $\mathrm{CO} 2$. Geochemistry, Geophysics, Geosystems, 2008, vol. 9, Iss. 8, Q08014.

48. Evans M.J., Derry L.A., France-Lanord C. Degassing of metamorphic carbon dioxide from the Nepal Himalaya. Geochemistry, Geophysics, Geosystems, 2008, vol. 9, Iss. 4, Q04021.

49. Dominova I.N., Kublanov I.V., Podosokorskaya O.A., Derbikova K.S., Patrushev M.V., Toshchakov S.V. Complete genomic sequence of «Thermofilum adornatus» strain 1910bT, a hyperthermophilic anaerobic organotrophic crenarchaeon. Genome Announcements, 2013, vol. 1, Iss. 5, e00726-13.

50. Kochetkova T.V., Kublanov I.V., Toshchakov S.V., Osburn M.R., Novikov A.A., Bonch-Osmolovskaya E.A., Perevalova A.A. Thermogladius calderae gen. nov., sp. nov., an anaerobic, hyperthermophilic crenarchaeote from a Kamchatka hot spring. International Journal of Systematic and Evolutionary Microbiology, 2016, vol. 66, Iss. 3, pp. 1407-1412.

51. Podosokorskaya O.A., Kadnikov V.V., Gavrilov S.N., Mardanov A.V., Merkel A.Y., Karnachuk O.V., Ravin N.V., BonchOsmolovskaya E.A., Kublanov I.V. Characterization of Melioribacter roseus gen. nov., sp. nov., a novel facultatively anaerobic thermophilic cellulolytic bacterium from the class Ignavibacteria, and a proposal of a novel bacterial phylum Ignavibacteriae. Environmental Microbiology, 2013, vol. 15, Iss. 6, pp. 1759-1771.

52. Bonch-Osmolovskaya E., Elcheninov A., Zayulina K., Kublanov I. New thermophilic prokaryotes with hydrolytic activities. Microbiology Australia, 2018, vol. 39, Iss. 3, pp. 122-125.
53. Schmidt G., Najem S.A., Isenbeck-Schröter M., Freundt F., Kraml M., Eichstadter R., Aeschbach W. 87Sr/86Sr ratios in shallow and deep aquifers and thermal water from the eastern boundary fault of the Northern Upper Rhine Graben at the Heidelberg Basin, Germany. Procedia Earth and Planetary Science, 2017, vol. 17, pp. 108-111.

54. Petelet-Giraud E., Négrel P., Casanova J. Tracing Mixings and Water-Rock Interactions in the Loire River Basin (France): 8180 $\delta 2 \mathrm{H}$ and $87 \mathrm{Sr} / 86 \mathrm{Sr}$. Procedia Earth and Planetary Science, 2017, vol. 17, pp. 794-797.

55. Hans U., Kleine T., Bourdon B. Rb-Sr chronology of volatile depletion in differentiated protoplanets: BABI, ADOR and ALL revisited. Earth and Planetary Science Letters, 2013, vol. 374, pp. 204-214.

56. McArthur J.M., Howarth R.J., Shields G.A. The geologic time scale. Chapter 7 - Strontium isotope stratigraphy. Amsterdam, Elsiver, 2012. pp. 127-144.

57. Alexeev S., Alexeeva L., Shouakar-Stash O. Strontium isotopic ratio in brines from the north-east of the Angara-Lenskiy artesian basin. E3S Web of Conferences, 2019, vol. 98, 12001.

58. Weihua W., Mingzhao S., Xiang J., Shuyi Q. Sr isotopic characteristics and fractionation during weathering of a small granitic watershed system in the Jiuhua Mountains (eastern China). Journal of Hydrology, 2019, vol. 568, pp. 135-146.

59. Korte C., Ullmann C.V. Permian strontium isotope stratigraphy. Geological Society London Special Publications, 2016, vol. 450, Iss. 1, pp. 105-118.

60. Banner J.L. Radiogenic isotopes: systematics and applications to earth surface processes and chemical stratigraphy. Earth-Science Reviews, 2004, vol.65, Iss. 3-4, pp. 141-194.

61. Armstrong S.C., Sturchio N.C., Hendry M.J. Strontium isotopic evidence on the chemical evolution of pore waters in the Milk River aquifer, Alberta, Canada. Applied Geochemistry, 1998, vol. 13 , pp. $463-475$.

62. Luis A.T., Duraes N., Ferreira da Silva E., Ribeiro S., Silva A.J.F., Patinha C., Almeida S.F.P., Azevedo M.R. Tracking multiple Sr sources through variations in $87 \mathrm{Sr} / 86 \mathrm{Sr}$ ratios of surface waters from the Aljustrel massive sulphide mining area: geological versus anthropogenic inputs. Applied Geochemistry, 2019, vol. 102, pp. $108-120$.

63. Novikov D.A. Hydrogeochemistry of the Arctic areas of Siberian petroleum basins. Petroleum Exploration and Development, 2017, vol. 44 , no. 5 , pp. $780-786$

64. Novikov D.A. Genetic classification of subsurface waters and brines of Arctic regions of Siberia. IOP Conference Series: Earth and Environmental Science, 2018, vol. 193, 012049.

Received: 30 August 2020.

\section{Information about the authors}

Dmitry A. Novikov, Cand. Sc., head of the laboratory, Trofimuk Institute of Petroleum Geology and Geophysics of Siberian Branch of Russian Academy of Sciences; associate professor, Novosibirsk State University.

Aleksandr N. Pyrayev, Cand. Sc., researcher, Institute of Geology and Mineralogy of SB of RAS; assistant, Novosibirsk State University.

Anatoliy $\boldsymbol{V}$. Chernykh, research associate, Trofimuk Institute of Petroleum Geology and Geophysics of Siberian Branch of Russian Academy of Sciences.

Fedor F. Dultsev, research associate, Trofimuk Institute of Petroleum Geology and Geophysics of Siberian Branch of Russian Academy of Sciences.

Svetlana V. Ryzhkova, Cand. Sc., senior researcher, Trofimuk Institute of Petroleum Geology and Geophysics of Siberian Branch of Russian Academy of Sciences; associate professor, Novosibirsk State University. 